\title{
Roles of thromboxane $A_{2}$ and prostacyclin in the development of atherosclerosis in apoE-deficient mice
}

\author{
Takuya Kobayashi, ${ }^{1}$ Yoshio Tahara, ${ }^{1}$ Mayumi Matsumoto, ${ }^{1}$ Masako Iguchi, ${ }^{1}$ Hideto Sano, ${ }^{2}$ \\ Toshinori Murayama, ${ }^{3}$ Hidenori Arai, ${ }^{2}$ Hiroji Oida, ${ }^{4}$ Takami Yurugi-Kobayashi, ${ }^{5}$ Jun K. Yamashita, ${ }^{5}$ \\ Hiroyuki Katagiri, 6,7 Masataka Majima, ${ }^{7}$ Masayuki Yokode,, ${ }^{3}$ Toru Kita, ${ }^{8}$ and Shuh Narumiya ${ }^{1}$ \\ 1Department of Pharmacology, ${ }^{2}$ Department of Geriatric Medicine, and ${ }^{3}$ Department of Clinical Innovative Medicine, Kyoto University \\ Faculty of Medicine, Kyoto, Japan. ${ }^{4}$ Fukui Safety Research Institute, Ono Pharmaceutical Co., Fukui, Japan. ${ }^{5}$ Laboratory of Stem Cell Differentiation, \\ Kyoto University Faculty of Medicine, Kyoto, Japan. ${ }^{6}$ Department of Surgery and ${ }^{7 D}$ Department of Pharmacology, Kitasato University \\ School of Medicine, Kanagawa, Japan. ${ }^{8}$ Department of Cardiovascular Medicine, Kyoto University Faculty of Medicine, Kyoto, Japan.
}

\begin{abstract}
Production of thromboxane (TX) $\mathrm{A}_{2}$ and $\mathrm{PG} \mathrm{I}_{2}$ /prostacyclin ( $\left.\mathrm{PGI}_{2}\right)$ is increased in patients with atherosclerosis. However, their roles in atherogenesis have not been critically defined. To examine this issue, we cross-bred atherosclerosis-prone apoE-deficient mice with mice deficient in either the TXA receptor (TP) or the PGI receptor (IP). Although they showed levels of serum cholesterol and triglyceride similar to those of apoE-deficient mice, $a p o E^{-/-} T P^{-/-}$mice exhibited a significant delay in atherogenesis, and $a p o E^{-/-} I P^{-/-}$mice exhibited a significant acceleration in atherogenesis compared with mice deficient in apoE alone. The plaques in $a p o E^{-/-I P^{-/-}}$mice showed partial endothelial disruption and exhibited enhanced expression of ICAM-1 and decreased expression of platelet endothelial cell adhesion molecule 1 (PECAM-1) in the overlying endothelial cells compared with those of $a p o E^{-/-} \mathrm{TP}^{-/-}$mice. Platelet activation with thrombin ex vivo revealed higher and lower sensitivity for surface P-selectin expression in platelets of $a p o E^{-/-} I P^{-/-}$and $a p o E^{-/-} \mathrm{TP}^{-/-}$mice, respectively, than in those of $a p o E^{-/-}$mice. Intravital microscopy of the common carotid artery revealed a significantly greater number of leukocytes rolling on the vessel walls in $a p o E^{-/-I P^{-/-}}$mice than in either $a p o E^{-/-} \mathrm{TP}^{-/-}$or $a p o E^{-/-}$mice. We conclude that $\mathrm{TXA}_{2}$ promotes and $\mathrm{PGI}_{2}$ prevents the initiation and progression of atherogenesis through control of platelet activation and leukocyte-endothelial cell interaction.
\end{abstract}

\section{Introduction}

It is now understood that atherosclerosis is an inflammation in the intima of large arteries that is triggered by high serum cholesterol and in which various types of cells including monocytes/ macrophages, endothelial cells (ECs), smooth muscle cells (SMCs), $\mathrm{T}$ cells, and blood platelets exert a complex array of interaction (1). A variety of substances including cytokines, chemokines, and growth factors are suggested to induce, amplify, and modify this inflammatory process. One group of these mediators is prostanoids, which are produced from arachidonic acid by the action of $\mathrm{COX}$ and include various types of PGs and thromboxane (TX). Involvement of prostanoids in acute inflammation has been well documented based on the finding that aspirin-like NSAIDs are specific COX inhibitors. Among prostanoids, $\mathrm{PG} \mathrm{I}_{2} /$ prostacyclin $\left(\mathrm{PGI}_{2}\right)$ and $\mathrm{TXA}_{2}$ have attracted particular attention for their importance in cardiovascular diseases: the former, generated by vascular ECs, is a potent platelet inhibitor and vasodilator, and the latter, released from activated platelets, is a potent vasoconstrictor and platelet-aggregating agent. Indeed, low-dose aspirin that pref-

Nonstandard abbreviations used: EC, endothelial cell; HDLC, HDL-cholesterol; IP, PGI receptor; LDLC, LDL-cholesterol; LDLR, LDL receptor; PECAM-1, platelet endothelial cell adhesion molecule 1; PFA, paraformaldehyde; $\mathrm{PGI}_{2}, \mathrm{PG}$ $\mathrm{I}_{2}$ /prostacyclin; PRP, platelet-rich plasma; SMC, smooth muscle cell; TC, total cholesterol; TG, total triglyceride; TP, TXA receptor; TX, thromboxane; VLDLC, VLDL-cholesterol; vWF, von Willebrand factor.

Conflict of interest: The authors have declared that no conflict of interest exists.

Citation for this article: J. Clin. Invest. 114:784-794 (2004)

doi:10.1172/JCI200421446 erentially inhibits platelet-derived $\mathrm{TXA}_{2}$ over endothelium-derived $\mathrm{PGI}_{2}$ has been used as anti-platelet therapy for the prevention of myocardial infarction and recurrence of strokes. Although biosynthesis of $\mathrm{PGI}_{2}$ and $\mathrm{TXA}_{2}$ is increased in patients with atherosclerosis $(2,3)$, the roles of these molecules in the initiation and progression of atherosclerosis have not yet been critically examined.

The role played by prostanoids in atherogenesis has been studied mostly by examining the effects of various drugs in mice deficient in either apoE (apoE $E^{-/-}$mice) $(4,5)$ or the LDL receptor (LDLR) (LDLR $R^{-/-}$mice) (6). One group of such pharmacological studies has used low doses of aspirin in atherosclerotic model animals to evaluate the contribution of $\mathrm{TXA}_{2}$. Cyrus et al. (7) fed $L D L R^{-/-}$mice a high-fat diet, treated the mice with low-dose aspirin, and found that this dose of aspirin significantly retarded the development of atherosclerotic lesions, with a $64 \%$ reduction in an en face analysis and $29 \%$ in a cross-sectional analysis. In contrast, Cayatte et al. (8) used aspirin in $a p o E^{-/-}$mice and did not find retardation in the development of atherosclerotic lesions. This discrepancy could be attributed to the higher dose of aspirin used in the latter study, which may have inhibited prostanoid production in cells other than platelets, particularly $\mathrm{PGI}_{2}$ in blood vessels. In the same study, Cayatte et al. (8) administered a TXA receptor (TP) antagonist, S-18886, to apoE $E^{-/-}$mice. They reported that administration of this drug indeed suppressed the extent of atherogenesis, but only marginally, by $21 \%$. The other group of pharmacological studies has used isoform-specific COX inhibitors and has evaluated the roles of prostanoids in atherogenesis. COX exists as two isoforms encoded by two distinct genes (9): COX-1 is constitu- 

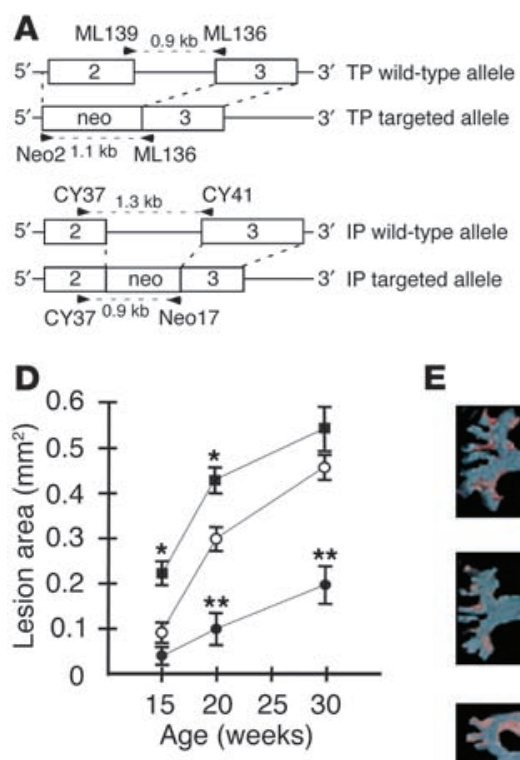

$\mathbf{F}$

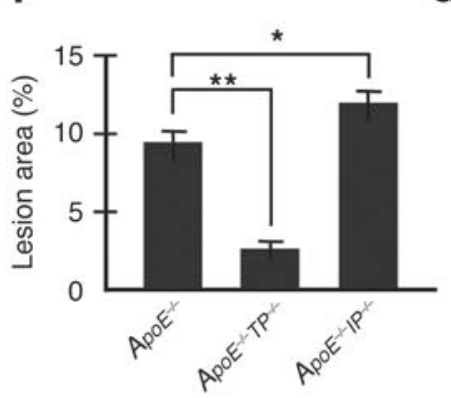

$\mathbf{E}$

G
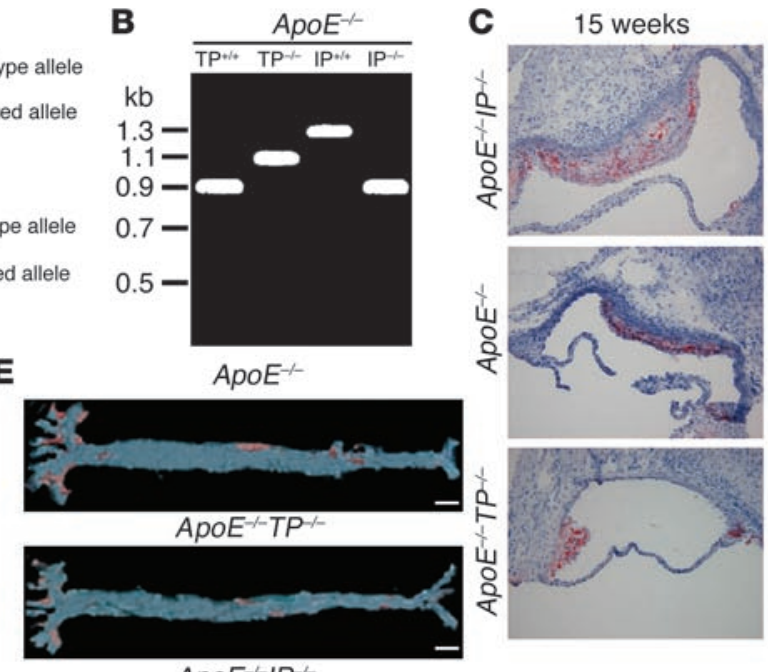

$A p o E^{--1 P^{-1}}$
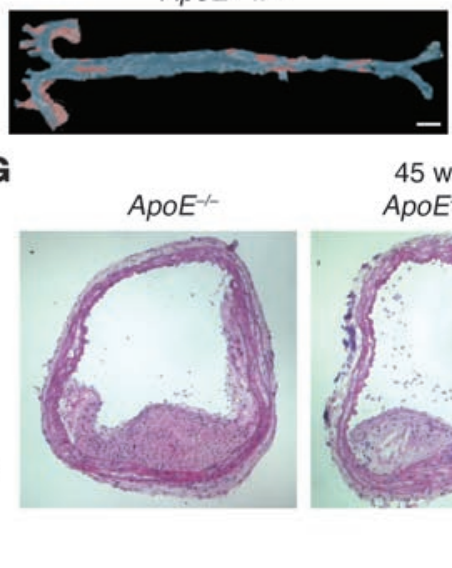

45 weeks ApoE ${ }^{-1}$ TP

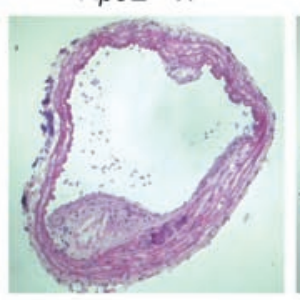

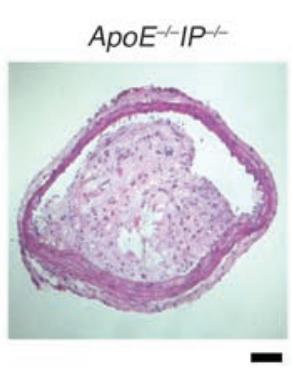

20 weeks
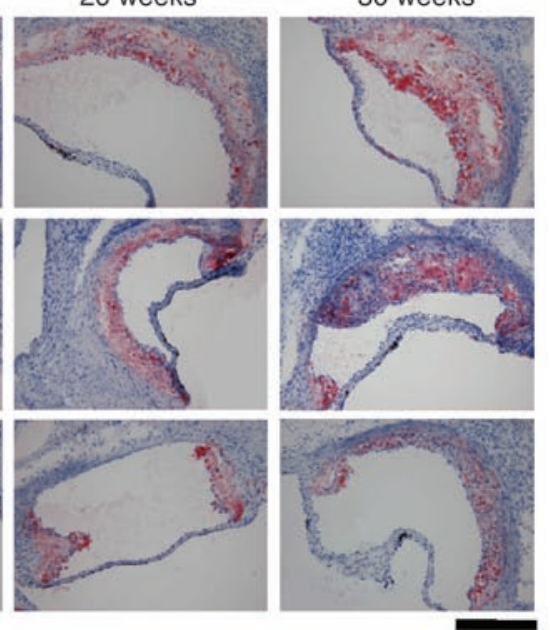

30 weeks
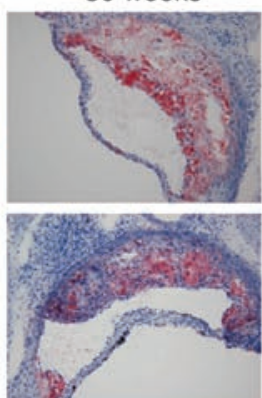

H

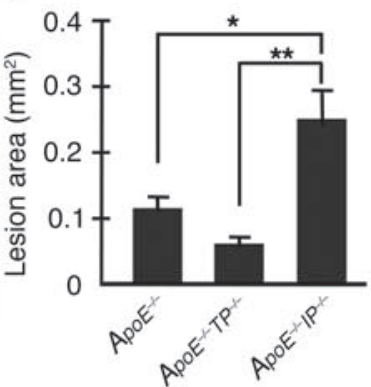

Figure 1

Generation and atherosclerotic lesions of $a p o E^{-/-} T P^{-/-}$and $a p o E^{-1-I P^{-/-}}$mice. (A) Strategy for PCR analysis of WT and targeted alleles of TP and IP. Primers are shown by arrowheads. Amplified fragments are shown by broken lines. Neo, neomycin-resistance gene. (B) Representa-

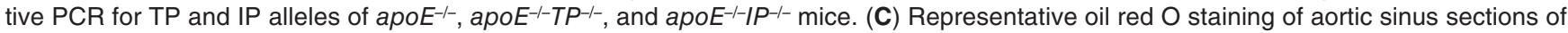
$a p o E^{-/-}$(middle), apoE $E^{-/-} T P^{-/-}$(lower), and apoE $E^{-/-I P^{-/-}}$(upper) mice. Scale bar: $200 \mathrm{um}$. (D) Time course of atherosclerotic lesion development in $a p o E^{-/-}$(open circles), apo $E^{-/-} T P^{-/-}$(filled circles), and apoE $E^{--I} I P^{-/-}$(filled squares) mice. Data are means \pm SEM ( $n=10$ for $15-$ week-old

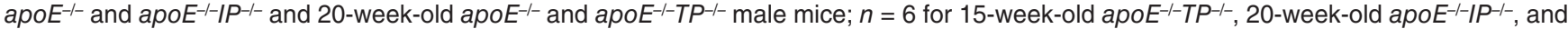

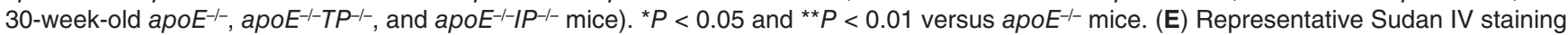

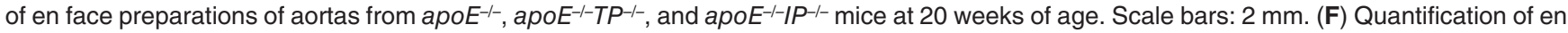
face atherosclerotic lesions in apoE $E^{-/-}$, apo $E^{-/-} T P^{-/-}$and $a p o E^{-/-I P^{-/}}$mice at 20 weeks of age. Data are means $\pm \mathrm{SEM}\left(n=5\right.$ each). ${ }^{*} P<0.05$ and ${ }^{\star \star} P<0.01$ for bracketed comparisons. (G) Representative hematoxylin and eosin staining of innominate artery sections of apoE $E^{-/-}$, apo $E^{-/-} T P^{-/-}$, and $a p o E^{-/-I P^{-/-}}$mice at 45 weeks of age. Scale bar: $20 \mu \mathrm{m}$. (H) Quantitative analysis of innominate atherosclerotic areas in apoE $E^{-/-}$, apoE $E^{-/-} T P^{-/-}$,

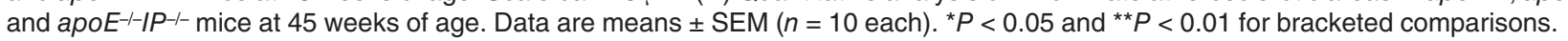

tively expressed in most tissues and mediates basal physiological functions, while COX-2 is induced by various types of stimuli and works "on demand" in such conditions as inflammation. There is now substantial evidence that the majority of $\mathrm{PGI}_{2}$ is produced by COX-2 in vascular ECs, whereas production of $\mathrm{TXA}_{2}$ by platelets is catalyzed by COX-1 (10). The COX-2-catalyzed $\mathrm{PGI}_{2}$ production probably reflects induction of COX-2 by hemodynamic shear stress in the vasculature (11). The issue of whether COX-2-derived $\mathrm{PGI}_{2}$ exerts any protective effect on atherosclerosis is important, given that many juvenile patients with arthritis are treated with selective COX-2 inhibitors (12) and a large-scale study (VIGOR) indicated an increased tendency for cardiovascular accidents associated with the use of such drugs versus the nonselective COX inhibitor naproxen (discussed in ref. 13). Experiments examining the effects of COX-2 inhibitors in atherogenesis have yielded conflicting results. One study in which an MF-tricyclic was administered to apo $E^{-/-}$mice found exaggeration of atherosclerosis (14), and one study examining the effect of rofecoxib in $L D L R^{-/-}$mice detected a small but significant suppression in the development of atherosclerosis (15). The former study (14) did not specify the gender of the mice studied and may be difficult to interpret. However, two other studies, one of nimesulide in $L D L R^{-/-}$mice (16) and the other of SC-236 in apoE $E^{-/-}$mice (17), did not find significant effects. These studies, except for the study using MF-tricyclic (14), all detected similar suppression of $\mathrm{PGI}_{2}$ production in animals given these drugs. However, the suppression remained partial, 
Table 1

Plasma cholesterol and triglyceride levels

\begin{tabular}{|c|c|c|c|c|c|}
\hline $\begin{array}{l}\text { Mouse } \\
\text { (mg/dl) }\end{array}$ & $\mathrm{TC}(\mathrm{mg} / \mathrm{dl})$ & $\mathrm{TG}(\mathrm{mg} / \mathrm{dl})$ & VLDLC (mg/dl) & $\operatorname{LDLC}(\mathrm{mg} / \mathrm{dl})$ & HDLC \\
\hline C57BL/6 $(n=8)$ & $99 \pm 5$ & $57 \pm 4$ & $6 \pm 1$ & $24 \pm 3$ & $58 \pm 4$ \\
\hline$T P^{-1-}(n=8)$ & $85 \pm 9$ & $50 \pm 5$ & $8 \pm 1$ & $19 \pm 3$ & $54 \pm 4$ \\
\hline$I P^{-/-}(n=8)$ & $90 \pm 9$ & $55 \pm 6$ & $7 \pm 1$ & $22 \pm 3$ & $56 \pm 4$ \\
\hline $\operatorname{ApoE}^{-/-}(n=8)$ & $535 \pm 43^{A}$ & $102 \pm 6^{A}$ & $381 \pm 36^{A}$ & $127 \pm 5^{A}$ & $27 \pm 4$ \\
\hline$A p o E^{-/-} T P^{-/-}(n=8)$ & $595 \pm 53^{A}$ & $105 \pm 10^{A}$ & $395 \pm 60^{A}$ & $138 \pm 5^{A}$ & $22 \pm 4^{B}$ \\
\hline$A p o E^{-/-} \mid P^{-/-}(n=8)$ & $588 \pm 52^{A}$ & $103 \pm 8^{A}$ & $430 \pm 44 A$ & $135 \pm 11 \mathrm{~A}$ & $22 \pm 4$ \\
\hline
\end{tabular}

All data are shown as mean \pm SEM. ${ }^{A} P<0.01$ versus $C 57 B L / 6$. ${ }^{B} P<0.05$ versus C57BL/6.

sis (Figure 1, A and B) and was confirmed by examination of the platelet response to a TP or IP agonist (data not shown). The TP agonist I-BOP induced aggregation of platelets from $a p o E^{-/-}$mice but not of platelets from $a p o E^{-/-} \mathrm{TP}^{-/-}$mice, whereas thrombin-induced aggregation occurred similarly in platelets from apo $E^{-/-}$and apo $E^{-/-} \mathrm{TP}^{-/-}$mice. In contrast, the IP agonist cicaprost inhibited I-BOP-induced platelet aggregation in apoE $E^{-/-}$mice and this response was lost in apoE $E^{-/-I P^{-/-}}$platelets. The apoE deficien$\mathrm{cy}$ in these mice was verified by measure-

supporting a view that both COX-1 and COX-2 contribute to $\mathrm{PGI}_{2}$ production under pathological conditions such as atherosclerosis (3). Thus, pharmacological approaches using various drugs have produced variable and inconclusive results and have failed to provide a cohesive picture on the contribution of prostanoids, including $\mathrm{PGI}_{2}$ and $\mathrm{TXA}_{2}$, to atherogenesis. This probably reflects the inherent limitations associated with pharmacological studies, such as differences in the potency and specificity of individual drugs and differences in the experimental protocols and animal models. Moreover, it is difficult in principle to evaluate contribution of each prostanoid by the use of COX inhibitors, because each isoform is capable of producing more than one type of prostanoid in a variety of tissues. For example, $\mathrm{TXA}_{2}$ is produced not only by COX-1 in blood platelets but also by COX-2 in macrophages, which is also believed to produce $\mathrm{PGE}_{2}$ in atheromatous plaques. The importance of COX-2 in macrophages was suggested by the reduction in atherogenesis found in $L D L R^{-/-}$mice reconstituted with $C O X-2^{-/-}$fetal liver cells (15).

In order to conquer these limitations, we have examined the development of atherosclerosis in mice deficient in prostanoid receptors for individual molecules $\left(\mathrm{TXA}_{2}\right.$ and $\left.\mathrm{PGI}_{2}\right)$. $\mathrm{TXA}_{2}$ and $\mathrm{PGI}_{2}$ exert their effects through interaction with cell surface receptors specific to each molecule, TP and the PGI receptor (IP), respectively (18). These receptors are encoded by distinct genes and are expressed differentially in the body. With the use of homologous recombination, we have generated mice that lack either TP or IP individually and have subjected the mice to models of various diseases to analyze the roles of TXA 2 and $\mathrm{PGI}_{2}$ (19-29). In this work, we have cross-bred TP- and IP-deficient $\left(\mathrm{TP}^{-/-}\right.$and $\left.I \mathrm{P}^{-/-}\right)$mice with apoE $E^{-/-}$mice and have analyzed the roles played by $\mathrm{TXA}_{2}$ and $\mathrm{PGI}_{2}$ in atherosclerotic lesion development.

\section{Results}

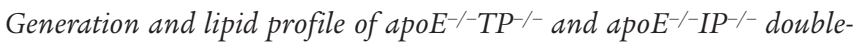
$\mathrm{KO}$ mice. $\mathrm{TP}^{-/-}$and $I \mathrm{P}^{-/-}$mice that had been backcrossed to the $\mathrm{C} 57 \mathrm{BL} / 6$ background 10 times each were bred with apo $E^{-/-}$mice that had been backcrossed to the C57BL/ 6 background 5 times. The resultant heterozygous mice, apoE $E^{+/-} \mathrm{TP}^{+/-}$or $a p o E^{+/-} I \mathrm{P}^{+/-}$mice, were cross-bred with each other, and compound mice deficient in both apoE and TP or both apoE and IP were generated. The genes encoding IP and apoE are both located on chromosome 7, with a genetic interval of approximately $1.5 \mathrm{cM}$. To generate recombination between the genes encoding IP and apoE, we mated pairs of apoE $E^{+/-} I P^{+/-}$double-heterozygous mice and selected offspring null either for apoE or IP (about 1\% of the offspring) and cross-bred them with each other. Loss of TP or IP was assessed by PCR analy- ment of plasma cholesterol levels and PCR analysis. At 20 weeks of age, apo $E^{-/-} T P^{-/-}$and $a p o E^{-/-} I P^{-/-}$mice showed elevated levels of both total cholesterol (TC) and total triglyceride (TG) similar to those seen in apoE $E^{-/-}$mice (Table 1). Moreover, VLDL-cholesterol (VLDLC), LDL-cholesterol (LDLC), and HDL-cholesterol (HDLC) in apoE $E^{-/}$, apo $E^{-/-} T P^{-/-}$, and $a p o E^{-/-} I P^{-/-}$mice were almost identical. These findings suggest that loss of either TP or IP did not affect the hypercholesterolemia induced by apoE deficiency. apo $E^{-/-} \mathrm{TP}^{-/-}$ and $a p o E^{-/-} I P^{-/-}$mice were fertile and apparently healthy. All animals were maintained on a normal chow diet and gained weight in a similar manner (data not shown).

Atherosclerotic lesion development in apo $E^{-/-} \mathrm{TP}^{-/-}$and apo $E^{-/-} I P^{-/-}$ mice. We used male mice of the three strains (apo $E^{-/-}$, apo $E^{-/-} T P^{-/-}$, and $\left.a p o E^{-/-} I P^{-/-}\right)$and examined atherosclerotic lesion development by analysis of cross-sections of the proximal aorta, en face analysis of the total aorta, and analysis of cross-sections of the innominate artery. The cross-sectional analysis of the proximal aorta was performed in the first $360 \mu \mathrm{m}$ of the aortas of $a p o E^{-/-}, a p o E^{-/-} \mathrm{TP}^{-/-}$, and apo $E^{-/-I P^{-/}}$mice at 15,20 , and 30 weeks of age. Typical oil red $\mathrm{O}$ staining in each strain of mice at the respective age is shown in Figure $1 \mathrm{C}$. The quantitative analysis revealed significant acceleration and delay of lesion development in apo $E^{-/-} I P^{-/-}$and $a p o E^{-/-} \mathrm{TP}^{-/-}$ mice, respectively, compared with that in $a p o E^{-/-}$mice (Figure 1D). At 15 and 20 weeks of age, the lesion areas of $a p o E^{-/-} I P^{-/-}$mice $\left(0.206 \pm 0.016 \mathrm{~mm}^{2}\right.$ and $\left.0.420 \pm 0.017 \mathrm{~mm}^{2}\right)$ were augmented significantly by $131 \%$ and $45 \%$, respectively, compared with those of apo $E^{-/-}$mice $\left(0.089 \pm 0.015 \mathrm{~mm}^{2}\right.$ and $0.290 \pm 0.015 \mathrm{~mm}^{2} ; P<0.05$, Tukey's $t$ test following one-way ANOVA) (Figure 1D). After 20 weeks, lesion development in $a p o E^{-/-I P^{-/-}}$mice appeared to quickly reach a plateau and did not show a significant difference compared with that in $a p o E^{-/-}$mice at 30 weeks of age. In contrast, apoE $E^{-/-} \mathrm{TP}^{-/-}$ mice showed significant delay in the lesion development; their lesion areas at 20 and 30 weeks of age $\left(0.087 \pm 0.015 \mathrm{~mm}^{2}\right.$ and $\left.0.183 \pm 0.034 \mathrm{~mm}^{2}\right)$ were significantly suppressed, by $70 \%$ and $58 \%$, respectively, compared with those of $a p o E^{-/-}$mice $(0.290 \pm 0.015$ $\mathrm{mm}^{2}$ and $0.438 \pm 0.025 \mathrm{~mm}^{2} ; P<0.01$, Tukey's $t$ test following oneway ANOVA) (Figure 1D).

Apo $E^{-/-} I P^{-/-}$and $a p o E^{-/-} T P^{-/-}$mice showed enhancement and suppression, respectively, of atherogenesis not only locally in the aortic sinus but also globally throughout aorta. En face analysis of aortic preparations of mice at 20 weeks of age revealed significant augmentation and reduction in atherosclerotic area in $a p o E^{-/-} I P^{-/-}$and apo $E^{-/-} \mathrm{TP}^{-/-}$mice, respectively, compared with that of apoE $E^{-/-}$mice (Figure 1E); the average lesion size in apoE $E^{-/-} \mathrm{TP}^{-/-}$mice $(2.8 \% \pm 0.4 \%)$ was reduced $71 \%$ compared with that in $a p o E^{-/-}$mice $(9.6 \% \pm 0.9 \%$; $P<0.01$, Tukey's $t$ test following one-way ANOVA), while that in 
A
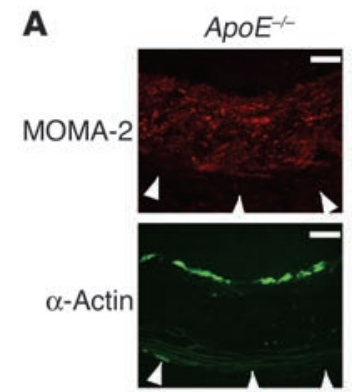

D

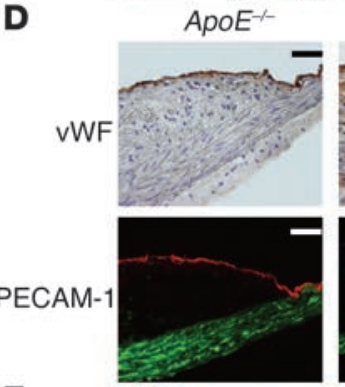

F
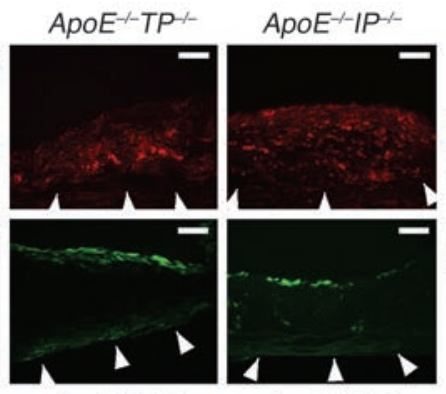

B

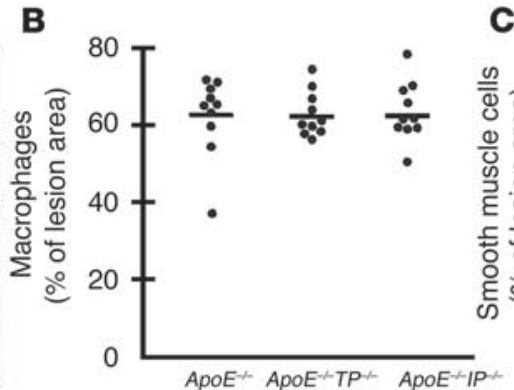

C
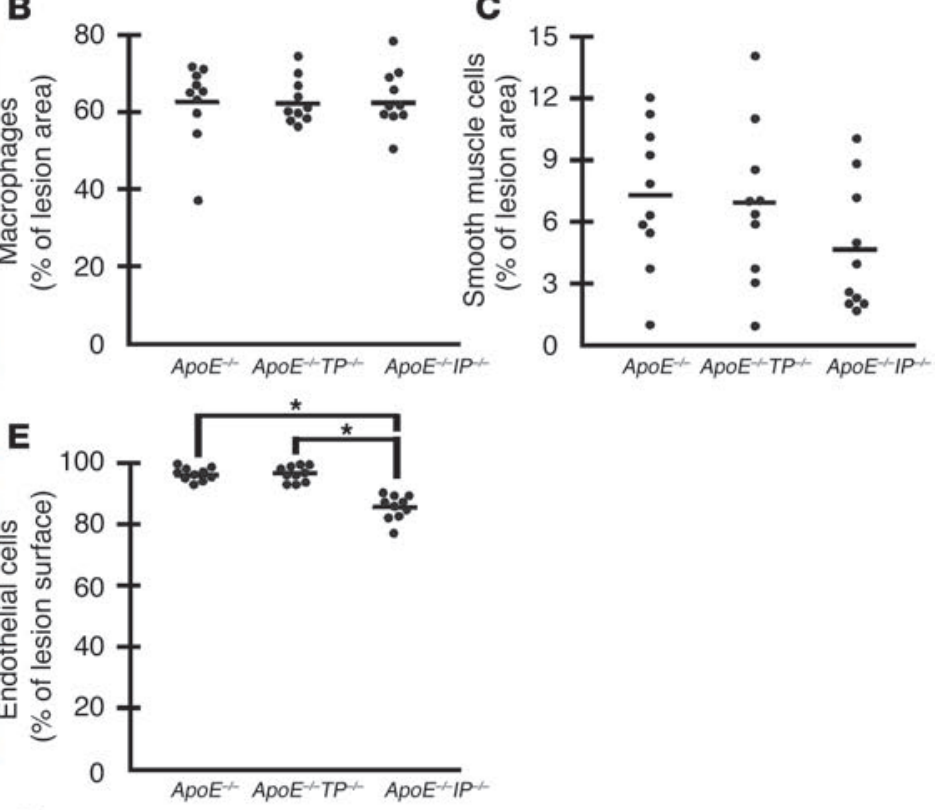

G
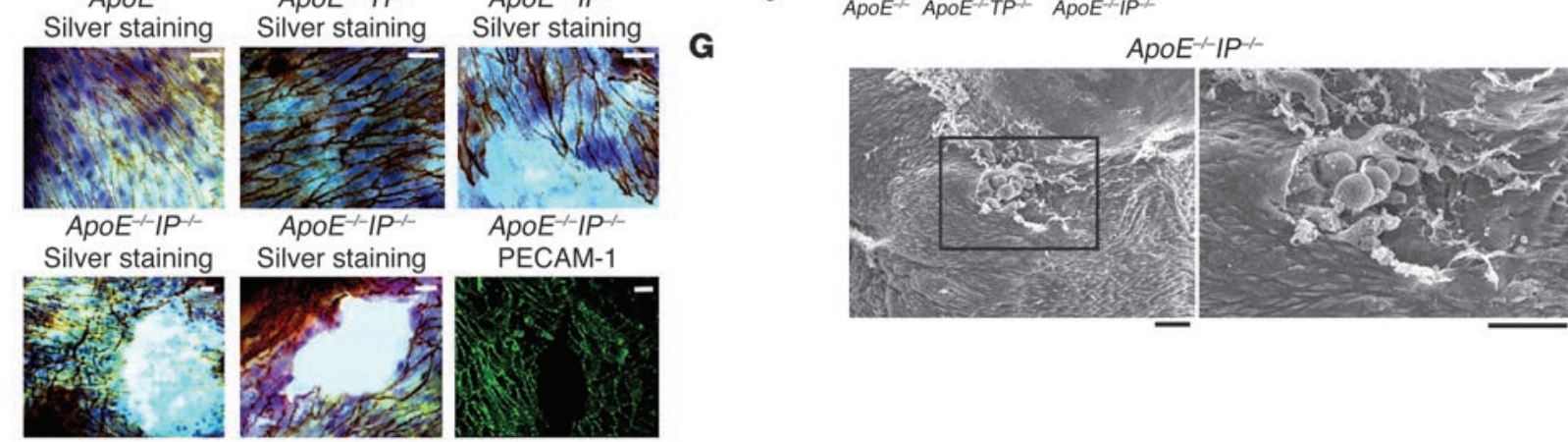

Silver staining

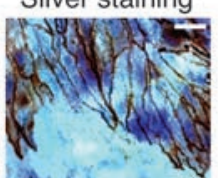

$A p o E^{-1-} \mid P^{-1}$

PECAM-1

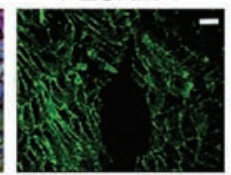

\section{Figure 2}

Effects of TP or IP deficiency on the abundance of macrophages and SMCs and EC integrity in aortic arch lesions of apoE-deficient mice at 20 weeks of age. (A) Representative immunostaining of macrophages and SMCs in aortic arch lesions of apoE $E^{-/-}$(left panels), apoE $E^{-/-} T P^{-/-}$(middle panels), and $a p o E^{--I} I P^{-/-}$(right panels) mice. Lesions were stained with specific antibodies for macrophages (MOMA-2; upper) and for SMCs ( $\alpha$-actin; lower). White arrowheads indicate the external elastic lamina. Scale bars: $20 \mu \mathrm{m}$. (B and C) Quantitative analysis of the abundance of

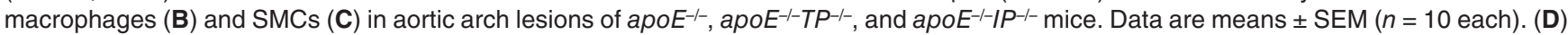

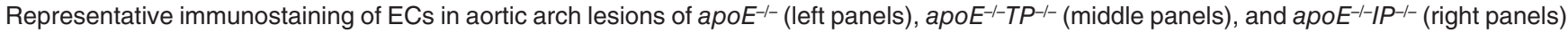
mice. Cross-sections were stained with specific antibodies for ECs (vWF, upper, and PECAM-1, red, lower) and SMCs ( $\alpha$-actin, green, lower). Black and white arrowheads indicate the site of endothelial disruption. Scale bars: $20 \mu \mathrm{m}$. (E) Quantitative analysis for endothelial integrity in aortic arch lesions of $a p o E^{-/-}$, apo $E^{-/-} T P^{-/-}$, and $a p o E^{--I} I P^{-/-}$mice by measurement of the vWF-positive signals overlying aortic lesions. Data are means $\pm \operatorname{SEM}\left(n=10\right.$ each). ${ }^{*} P<0.05$ for bracketed comparisons. (F) Representative en face staining of aortic arch lesions of apoE $E^{-/-}$,

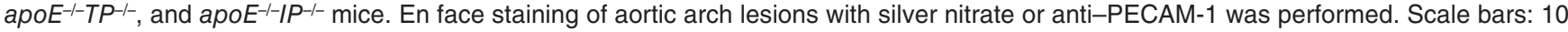
$\mu \mathrm{m}$. (G) Representative scanning electron micrographs of aortic arches of $a p o E^{--I} / P^{-/-}$mice. The right panel shows a higher magnification of the boxed area in the left panel. Scale bars: $50 \mu \mathrm{m}$.

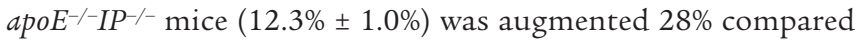
with that in apo $E^{-/-}$mice $(P<0.05$, Tukey's $t$ test following one-way ANOVA) (Figure 1F). Atherosclerotic lesions in apoE $E^{-/}$mice were seen in the lesser curvature of the aortic arch and at the ostium of the brachiocephalic artery as well as in the abdominal aorta. The lesions in apo $E^{-/-} \mathrm{TP}^{-/-}$at this age were limited mostly to the aortic arch region, where the extent was much less. In contrast, atherosclerotic lesions in apoE $E^{-/-I P^{-/-}}$mice were more extensive than in $a p o E^{-/-}$mice in every region examined (Figure $1 \mathrm{E}$ ).

Although analysis of atherogenesis in $\mathrm{apot}^{-/-}$mice is carried out mostly in the aorta, atherosclerotic lesions in this strain of mice are not limited to the aorta. We noted the atherosclerotic lesion at the ostium of the brachiocephalic (innominate) artery in our en face analysis of 20-week-old mice described above. Recently, Rosenfeld et al. (30) examined the distribution of atherosclerotic lesions throughout the arterial tree of $a p o E^{-/-}$mice and found a highly advanced, clinically significant lesion in the innominate artery in mice 30-60 weeks of age. We therefore examined atherosclerotic lesion development in the innominate artery by cross-sectional

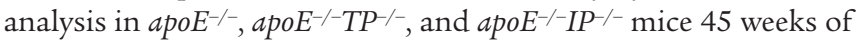
age. As shown in the hematoxylin and eosin staining in Figure $1 \mathrm{G}$, the lesion was found in all three strains of mice but the extent differed significantly. Whereas the plaques protruded into the arterial lumen only partially in $a p o E^{-/-}$and $a p o E^{-/-} T P^{-/-}$mice, those in 
A
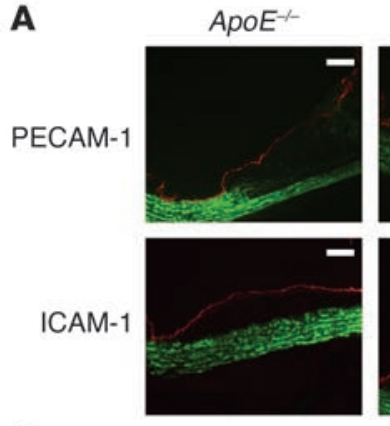

C
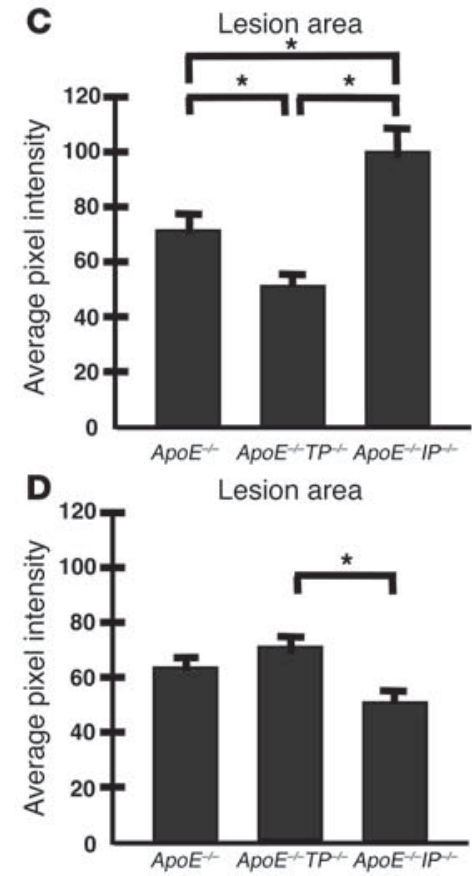

$A p o E^{-1-T P^{--}}$
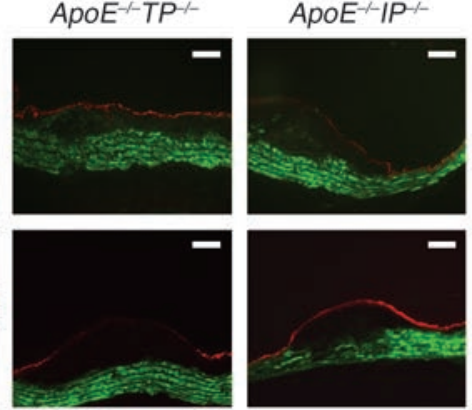

Intact area
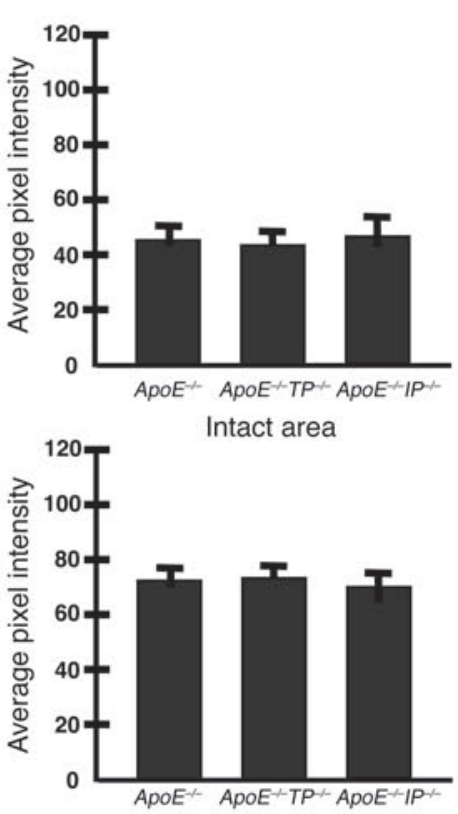

B

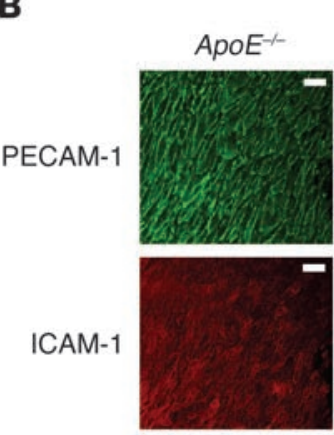

Lesion area
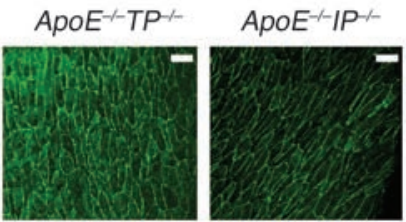

Merge
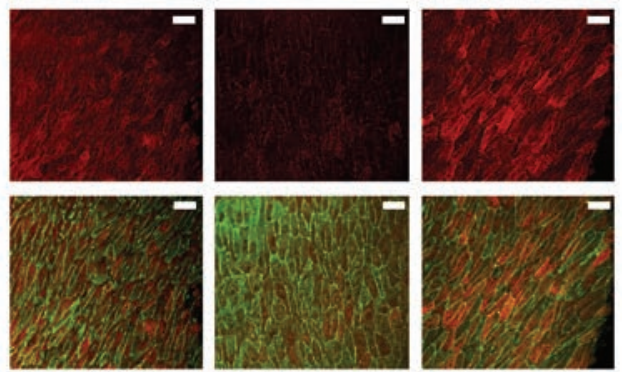

Intact area

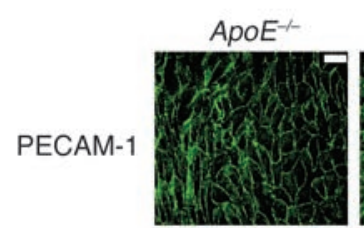

$A p o E^{-/} T P^{-/}$

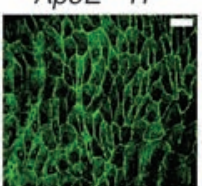

$A p o E^{-/-} \mid P^{-/}$

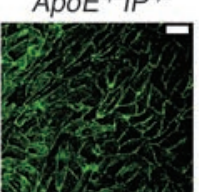

ICAM-1
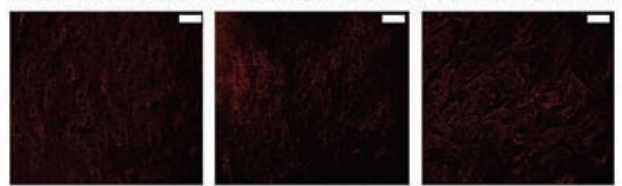

Merge
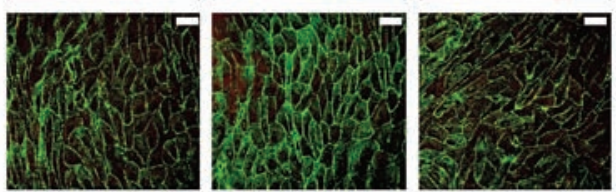

Figure 3

Effects of TP or IP deficiency on ICAM-1 and PECAM-1 expression in the ECs overlying atheromatous lesions of apoE-deficient mice. (A) Rep-

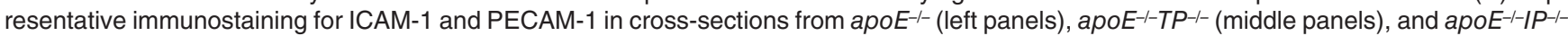
(right panels) mice. Mice were sacrificed at 20 weeks of age. Cross-sections were stained with specific antibodies against ICAM-1 (red; lower panels), PECAM-1 (red; upper panels), and smooth muscle $\alpha$-actin (green). Scale bars: $20 \mu \mathrm{m}$. (B) Representative immunostaining of aortic arch lesions and neighboring intact areas for ICAM-1 and PECAM-1 in en face preparations of apo $E^{-/-}$(left panels), apoE $E^{-/-T P^{-/-}}$(middle panels)

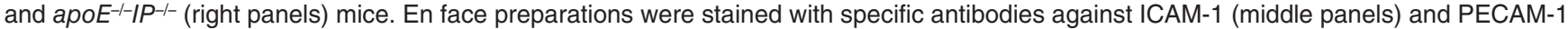
(upper panels). Mice were sacrificed at 20 weeks of age. Scale bars: $10 \mu \mathrm{m}$. Merge, merged images. (C and D) Quantification of ICAM-1 (C) and PECAM-1 (D) expression in ECs overlying aortic arch lesions and neighboring intact areas of apoE $E^{-/-}$, apo $E^{-/-} T P^{-/-}$, and apoE $E^{-/-I P^{-/-}}$mice. Data are means \pm SEM $\left(n=8\right.$ each). ${ }^{*} P<0.05$ and ${ }^{* *} P<0.01$ for bracketed comparisons.

apo $E^{-/-} I P^{-/-}$mice grew extensively to partially occlude the lumen. Quantitative analysis revealed significant acceleration and delay in lesion development, respectively, in $a p o E^{-/-} I P^{-/-}$and $a p o E^{-/-} \mathrm{TP}^{-/-}$ mice compared with apoE $E^{-/-}$mice (Figure $1 \mathrm{H}$ ).

Impaired EC integrity in atheromatous plaques of apo $E^{-/-} I P^{-/-}$mice. To investigate whether loss of TP or IP signaling had any effect on the cell composition in atheromatous plaques, we stained macrophages, SMCs, and ECs in the plaques at the aortic arches of 20-week-old mice with antibodies against the respective marker proteins. Quantification of macrophage and SMC abundance in the plaques and of endothelial integrity on the lesion surface was performed on the ten sections taken every $18 \mu \mathrm{m}$ as described in Methods (Figure 2). Cells staining positive for MOMA-2 were found throughout the plaques in all of $a p o E^{-/-}, a p o E^{-/-} T P^{-/-}$, and $a p o E^{-/-I P^{-/-}}$mice at this stage. Quantification revealed that MOMA-2-stained cells occupied about $60 \%$ of the total plaque area and there were no significant differences among the three strains (Figure 2, A and B). The fact that the area inside the plaque was stained homogenously with oil red O suggested that these MOMA-2-positive cells represented macrophage-derived foam cells and the space not occupied by macrophages represented mostly lipid cores. SMCs staining positive for $\alpha$-actin accumulated and formed a layer at the top of the lesion beneath the EC layer (Figure 2A and data not shown). Quantification revealed that they comprised about $7 \%$ of the total plaque area in $a p o E^{-/-}$and $a p o E^{-/-} \mathrm{TP}^{-/-}$mice (Figure $2 \mathrm{C}$ ). The proportion of SMCs in $a p o E^{-/-} I P^{-/-}$mice tended to be lower than that in the other two strains of mice, but there was no significant difference. This

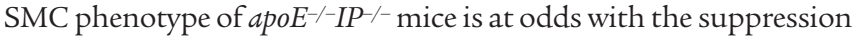




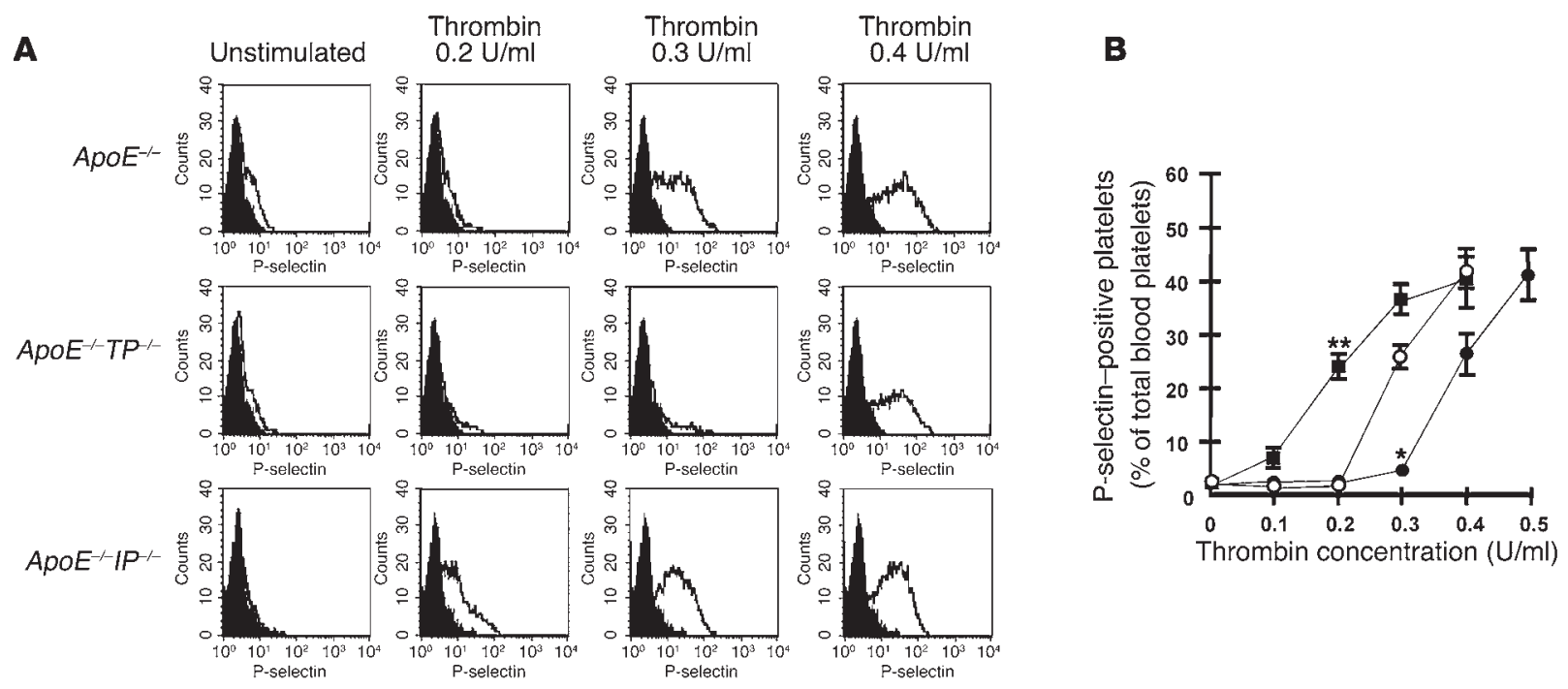

Figure 4

Platelet reactivity for thrombin-induced surface expression of P-selectin. (A) Representative histograms of thrombin-induced P-selectin expression in platelets from $a p o E^{-/-}$(upper panels), apoE $E^{-/-} T P^{-/-}$(middle panels), and apoE $E^{-/-I P^{-/-}}$(lower panels) mice. Platelets were either left unstimulated or were stimulated with $0.2,0.3$, or $0.4 \mathrm{U} / \mathrm{ml}$ of thrombin. They were then labeled with FITC-conjugated anti-P-selectin and were analyzed by flow cytometry. Filled histograms indicate background signal. (B) Quantification analysis. Concentration-dependent effect of thrombin for P-selectin expression was determined in platelets from apo $E^{-/-}$(open circles), apo $E^{-/-T P^{-/-}}$(filled circles), and apoE $E^{-/-I P^{-/-}}$(filled squares) mice. Data are means $\pm \operatorname{SEM}\left(n=9\right.$ each). ${ }^{*} P<0.05$ and ${ }^{* *} P<0.01$ versus apo $E^{-/-}$mice.

of SMC proliferation by a $\mathrm{PGI}_{2}$ analog (cicaprost) in vitro (22) as well as the enhanced proliferative response found in IP-deficient mice subjected to chronic hypoxia (23) or catheter-induced carotid vascular injury (31). Impaired SMC proliferation in the absence of IP may suggest that SMC proliferation is under more complex regulation in atherosclerosis or that it may be unique to the apoE-deficient mice. These points should be clarified in future studies.

EC integrity on the plaque surface was then examined by staining of the cross-sections for two endothelial markers: von Willebrand factor (vWF) and platelet endothelial cell adhesion molecule 1 (PECAM-1). As expected, the staining was seen as a linear signal in the EC layer over the plaques. There was occasional loss of staining of these two markers in the plaques of apo $E^{-/-} I P^{-/-}$mice, especially on the "shoulder" of atherosclerotic lesions (Figure 2D). In contrast, no such irregularity in EC staining on the plaque surface was seen in $a p o E^{-/-}$and $a p o E^{-/-} T P^{-/-}$mice. Quantification of $\mathrm{vWF}$ staining on the plaque surface revealed a significant reduction in apoE $E^{-/-I P^{-/}-}$ mice $(85.5 \% \pm 0.7 \%)$ compared with apo $E^{-/-}$mice $(98.0 \% \pm 0.5 \%, P<0.05$, Tukey's $t$ test following one-way ANOVA) and apo $E^{-/-} \mathrm{TP}^{-/-}$mice $(98.5 \% \pm 0.5 \%, P<0.05$, Tukey's $t$ test following one-way ANOVA) (Figure 2E). Compatible with these findings in the cross-sections, staining of en face preparations with silver nitrate as well as antiPECAM revealed loss of ECs which was consistently associated with the "shoulder" of a plaque in $a p o E^{-/-} I P^{-/-}$mice (Figure $2 \mathrm{~F}$ ). Such EC loss was rarely seen in $a p o E^{-/-}$and $a p o E^{-/-} \mathrm{TP}^{-/-}$mice (observations of 5 mice of each strain). Scanning electron microscopy of the aortic arch region revealed again focal endothelial disruption in the "shoulder" of atheromatous plaques of all of three $a p o E^{-/-I P^{-/}}$mice examined, while none of three apo $E^{-/-}$or $a p o E^{-/-} T P^{-/-}$mice showed such lesions. In some cases, the lesion of endothelial disruption formed a crater in which monocyte/macrophage-like cells accumulated (Figure $2 \mathrm{G}$ ). These findings suggest that the EC loss had already occurred in vivo and was not an artifact created during sample preparation.
ICAM-1 and PECAM-1 expression on ECs in apoE $E^{-/-} \mathrm{TP}^{-/-}$and

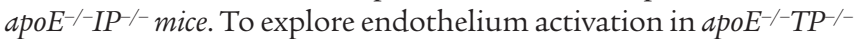
and $a p o E^{-1-} I P^{-/-}$mice, we stained for ICAM-1 and PECAM-1 in ECs overlying the lesions of the three lines of mice. In cross-sections, PECAM-1 expression was found more or less homogenously through the EC monolayer overlying the lesions, while ICAM-1 expression by endothelium was most intense at borders and the "shoulder" of the lesions in all of the three strains of mice (Figure $3 \mathrm{~A}$ ). We then performed quantitative analysis using en face confocal microscopy images (Figure 3B). In the ECs overlying the lesions, apoE $E^{-/-} T P^{-/-}$mice had a significant decrease in ICAM-1 expression $(53.9 \pm 1.8$ versus $73.1 \pm 4.1 ; P<0.05$, Tukey's $t$ test following one-way ANOVA; values measured in arbitrary units based on fluorescence intensity per pixel) compared with that of apo $E^{-/-}$mice, whereas ICAM-1 expression in apo $E^{-/-} I P^{-/-}$mice significantly increased $(100.5 \pm 7.6 ; P<0.01$, Tukey's $t$ test following one-way ANOVA) (Figure 3C). In contrast, there was no difference in ICAM-1 expression in ECs in intact areas among the three strains of mice, which was low compared with that in the atherosclerotic lesions. As for PECAM-1 expression in the atherosclerotic lesions, expression in apo $E^{-/-} \mathrm{TP}^{-/-}$mice or $\mathrm{apoE}^{-/-} \mathrm{IP}^{-/-}$mice tended to increase or decrease, respectively, compared with that in apoE $E^{-/-}$ mice, and there was a significant difference in expression between apoE $E^{-/-} I P^{-/-}$and apo $E^{-/-} T P^{-/-}$mice $(52.4 \pm 3.2$ versus $68.3 \pm 1.7$; $P<0.05$, Tukey's $t$ test following one-way ANOVA) (Figure 3D). There was also no difference in PECAM-1 expression in the ECs of intact areas among the three strains of mice.

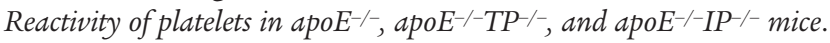
Because $\mathrm{TXA}_{2}$ and $\mathrm{PGI}_{2}$ are potent activators and suppressors, respectively, of blood platelets, chronic loss of their actions may cause alterations in platelet reactivity to an aggregating agent. Reactivity of

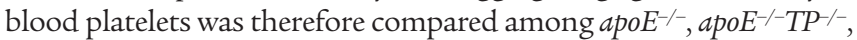

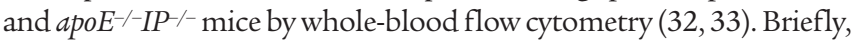


A

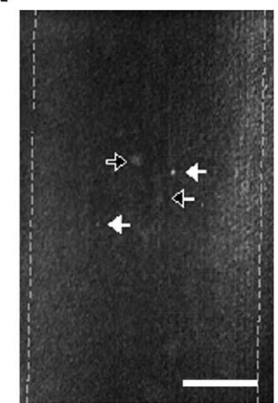

$A p o E^{-1-}$

B

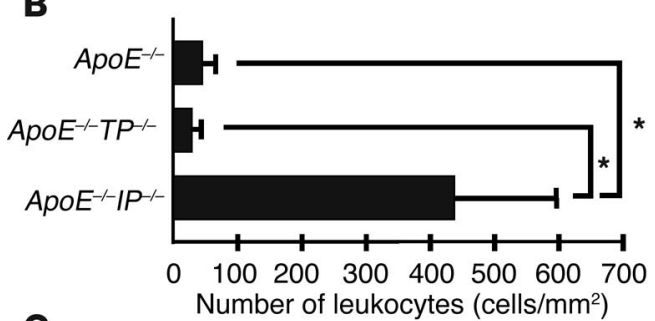

C

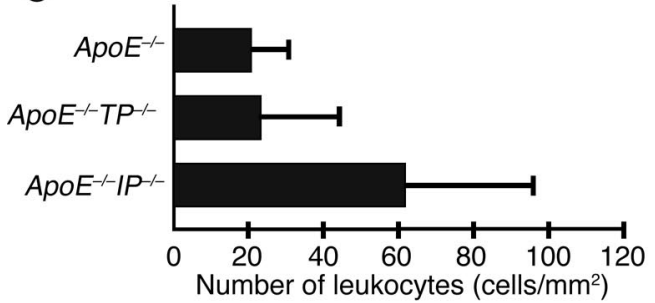

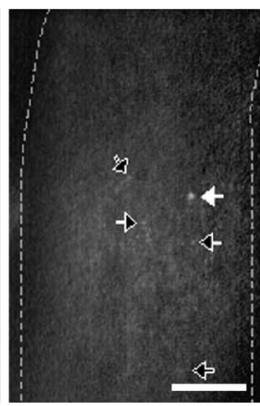

$A p o E^{--1} T P^{-/-}$

$A p o E^{-1-I P^{-1-}}$

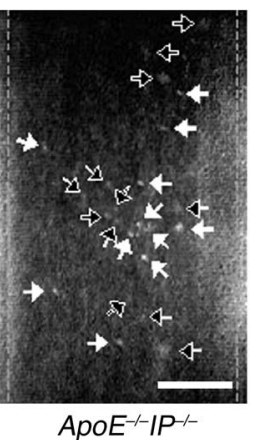

\section{Figure 5}

Intravital microscopy for leukocyte rolling and adhesion. (A) Fluorescence images of rolling and adherent leukocytes. Black and white arrows indicate rolling and adherent leukocytes, respectively. Vessel lumens are outlined by broken lines. Scale bars: $0.1 \mathrm{~mm}$. (B) Quantitative analysis of rolling leukocytes. Data are means \pm SEM $(n=5$ each). ${ }^{*} P<0.05$ versus apo $E^{-/-}$and $a p o E^{-/-} T P^{-/-}$mice. (C) Quantitative analysis for adherent leukocytes as described in $\mathbf{B}$.

\section{Discussion}

$\mathrm{TXA}_{2}$ and $\mathrm{PGI}_{2}$ are two major prostanoids in the cardiovascular system, being abundantly produced by blood platelets and vascular endothelium, respectively. Previous studies found that $\mathrm{TXA}_{2}$ and $\mathrm{PGI}_{2}$ biosynthesis is increased in patients with atherosclerosis $(2,3)$. In this work, we generated compound mice, $a p o E^{-/-} \mathrm{TP}^{-/-}$and apoE $E^{-/-} I P^{-/-}$, and examined the roles of $\mathrm{TXA}_{2}$ and $\mathrm{PGI}_{2}$ in the initiation and progression of atherosclerosis. $A p o E^{-/-}$mice develop a spectrum of atherosclerotic lesions similar to that of humans (34). They also show elevated production of $\mathrm{TXA}_{2}$ and $\mathrm{PGI}_{2}$, as

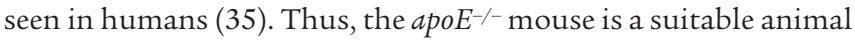
model for evaluation of the roles of $\mathrm{TXA}_{2}$ and $\mathrm{PGI}_{2}$ in atherosclerosis. Previously, the involvement of these prostanoids in atherosclerosis was examined by the use of various COX inhibitors in this and similar animal models. However, the results obtained by those studies were variable $(7,8,14-17)$. In addition, a study using a TP antagonist in apo $E^{-/-}$mice showed only a marginal reduction in atherogenesis (8). In contrast to those findings in the previous studies, our study here using genetically engineered mice has demonstrated significant suppression and significant enhancement of atherosclerosis in apoE $E^{-/-} \mathrm{TP}^{-/-}$and $a p o E^{-/-} I P^{-/-}$ mice, respectively, suggesting strongly proatherogenic and antiatherogenic actions of $\mathrm{TXA}_{2}$ and $\mathrm{PGI}_{2}$, respectively. TP deficiency suppressed the extent of atherosclerosis at both 20 and 30 weeks of age. Suppression of atherosclerosis by TP deficiency is much more robust ( $70 \%$ at 20 weeks of age and $58 \%$ at 30 weeks of age) than that found after treatment with the TP antagonist S-18886 (about 20\%) (8). We have also examined the effects of TP or IP deficiency on the development of vascular lesions in the innominate arteries of 45-week-old $a p o E^{-/-}$mice. Rosenfeld et al. (30) previously noted more-advanced vascular lesions in the innominate arteries in apo $E^{-/-}$mice. In this study we have not only confirmed their findings in $a p o E^{-/-}$mice but also found that this lesion was far more advanced in apoE $E^{-/-} I P^{-/-}$mice, whereas the disease progression appeared to be retarded in $a p o E^{-/-} \mathrm{TP}^{-/-}$mice.

It is noteworthy that atherogenesis was significantly accelerated and reached a plateau early in apoE $E^{-/-} I P^{-/-}$mice compared with apoE $E^{-/-}$mice. These results indicate that signaling from $\mathrm{PGI}_{2}$ to IP is important in preventing the initiation of atherosclerosis. Impaired $\mathrm{PGI}_{2}$ function, moreover, appeared to affect the progression and nature of atherosclerotic plaques. Our analysis detected frequent loss of ECs in the plaques of apo $E^{-/-} I P^{-/-}$mice. In addition to ECs, we also found that the abundance of SMCs tended to be lower in the plaques of $a p o E^{-/-} I P^{-/-}$mice (Figure 2). Lesions with impaired EC integrity and weaker fibrous caps are suggested to be prone to rupture (36). Recently, Cipollone and colleagues found that COX-2 and membrane-bound PGE synthetase are upregulated in macrophages in atheromatous plaques of humans and induce expression of matrix metalloproteinase- 9 and proposed that this pathway leads to plaque instability $(37,38)$. It is interesting in this context that $\mathrm{PGI}_{2}$ can suppress expression of 
this matrix metalloproteinase isoform in vitro and in vivo $(39,40)$. Lesion rupture, when it occurs in vivo, then precipitates thrombosis, which is further accelerated in the absence of IP. Disruption of IP is known to increase the risk of thrombosis (20). Thus, $\mathrm{PGI}_{2}$ appears to exert important inhibitory actions on the initiation and progression of atherosclerosis, and the reduction in $\mathrm{PGI}_{2}$ in the presence of normal $\mathrm{TXA}_{2}$ formation is likely to lead an increased risk of atherosclerosis and thrombosis. Currently, an important question concerning COX-2 inhibitors is whether the selective reduction in $\mathrm{PGI}_{2}$ increases the risk of atherosclerosis. Our findings support that conclusion. However, our findings cannot be directly extrapolated to the clinical outcome of patients treated with COX-2 inhibitors. Although the majority of $\mathrm{PGI}_{2}$ under basal conditions is derived from COX-2 catalysis, both COX-1 and COX-2 contribute to the increase in $\mathrm{PGI}_{2}$ in patients with atherosclerosis as well as in apoE $E^{-/-}$mice $(3,17)$, and selective inhibition of COX-2 usually results in only partial inhibition of $\mathrm{PGI}_{2}$ production (15-17). In addition, $\mathrm{TXA}_{2}$ can be derived also from COX-2 in atherosclerotic plaques. COX-2 is expressed by monocytes/macrophages in mouse atherosclerotic lesions (15). Macrophages contain TX synthase and release large amounts of $\mathrm{TXA}_{2}$ when transformed into foam cells with modified LDL (41).

What, then, are the underlying mechanisms of the actions of $\mathrm{TXA}_{2}$ and $\mathrm{PGI}_{2}$ in atherogenesis? Activation and inhibition of blood platelets by $\mathrm{TXA}_{2}$ and $\mathrm{PGI}_{2}$, respectively, may certainly be one of the mechanisms. Activated platelets were found in the circulating blood of patients with atherosclerosis (42-44) and hypercholesterolemia $(45,46)$. We have examined this issue by using whole-blood flow cytometry for thrombin-induced P-selectin expression in platelets (32). This method has been used frequently to evaluate platelet reactivity in patients with various cardiovascular disorders (33). Our analysis has revealed that platelets of apoE $E^{-/-} \mathrm{TP}^{-/-}$and $a p o E^{-/-}$ $I P^{-/-}$mice have lower and higher reactivity, respectively, than those of $a p o E^{-/-}$mice, which is consistent with the atherosclerotic phenotypes observed in the three strains of mice.

Here, we have further examined effects of TP or IP disruption on expression of adhesion molecules on ECs. Adhesion molecules on ECs play important roles in the migration of monocytes/ macrophages through the EC monolayer and the initiation of atheromatous plaques. Indeed, ICAM-1 is strongly expressed in atherosclerotic plaques of humans (47) and the level of soluble ICAM-1 correlates with the severity of atherosclerosis (48). In apo $E^{-/-}$mice, ICAM-1 expression is high in atherosclerosis-prone sites of the aorta, and deficiency in ICAM-1 in apoE-deficient mice significantly reduces atherosclerotic lesions (49). We have found that ICAM-1 expression on ECs overlying the plaques of apo $E^{-/-} T P^{-/-}$mice is significantly lower, while that of apo $E^{-/-} I P^{-/-}$ mice is significantly higher, than ICAM-1 expression in $a p o E^{-/-}$ mice (Figure 3). The changes in the ICAM-1 expression in the presence of TP or IP deficiency are consistent with the reported in vitro actions of $\mathrm{TXA}_{2}$ and $\mathrm{PGI}_{2}$. ICAM-1 expression is induced by proinflammatory cytokines from activated macrophages such as TNF- $\alpha$ or IL-1 $\beta$ (50). Signaling from $\mathrm{PGI}_{2}$ to IP is known to inhibit TNF- $\alpha$ production by activated macrophages (21) and to reduce IL-1-induced ICAM-1 expression on ECs (51). In contrast, stimulation of TP induces ICAM-1 expression in cultured ECs in vitro $(52,53)$, suggesting that $\mathrm{TXA}_{2}$ formed in situ in atheromatous plaques acts on ECs to induce ICAM-1 expression to amplify atherogenesis. Interestingly, $\mathrm{TXA}_{2}$ and $\mathrm{PGI}_{2}$ appear to have effects opposite to those of ICAM-1 on the expression of
PECAM-1 on the plaque ECs, which was up- and downregulated in apoE $E^{-/-} \mathrm{TP}^{-/-}$and $a p o E^{-/-} I P^{-/-}$mice, respectively. PECAM-1 was first described as an adhesion molecule essential in the transmigration of leukocytes through endothelial monolayer (54). However, recent analyses of PECAM-1/- mice in various models showed that PECAM-1 deficiency did not block but instead enhanced leukocyte accumulation at inflammation sites (55-57). Given its intracellular domain, PECAM-1 is now suggested to be an inhibitory signaling molecule (58). Intriguingly, regulation of PECAM-1 expression is opposite to that of ICAM-1. For example, a previous report showed that the expression of PECAM-1 and ICAM-1 on cultured human umbilical vein ECs was down- and upregulated, respectively, after activation with TNF- $\alpha$ plus IFN- $\gamma$ (59). Such opposite modes of expression may explain the changes in the patterns of ICAM- 1 and PECAM-1 expression found in the atherosclerosis phenotypes of apo $E^{-/-} T P^{-/-}$and apo $E^{-/-} I P^{-/-}$mice.

The above findings on the reactivity of platelets and the expression of adhesion molecules in ECs in $a p o E^{-/-}, a p o E^{-/-} \mathrm{TP}^{-/-}$, and apo $E^{-/-} I P^{-/-}$mice suggest that TP or IP deficiency can affect the interaction of ECs with platelets and leukocytes. We examined this issue by intravital microscopy. Although we did not detect significant platelet adhesion to the blood vessels of any of the three lines of mice under basal conditions, we found significant leukocyte adherence to the wall of the common carotid artery in apo $E^{-/-} I P^{-1-}$ mice. This may be relevant to the higher platelet reactivity and enhanced ICAM-1 expression in this line of animals. Platelet P-selectin is suggested to play an important role in mediating the leukocyte-EC interaction (60). It may be also relevant to the EC disruption observed in apoE $E^{-/-I P^{-/}-}$mice.

In conclusion, using the IP-deficient and TP-deficient mice, we were able to evaluate separately the contributions of $\mathrm{PGI}_{2}$ and $\mathrm{TXA}_{2}$ to the development of atherosclerosis. The information presented here will aid in the interpretation of clinical findings and the evaluation of risk in atherosclerotic patients treated with various drugs modulating the arachidonate cascade. Our findings also indicate that the administration of PGI mimetics and TP antagonists may be useful in the prevention of atherosclerosis. This line of genetic approach may also help to identify the contributions of PGs other than $\mathrm{PGI}_{2}$ and $\mathrm{TXA}_{2}$ to atherosclerosis.

\section{Methods}

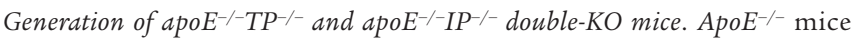
$(129 \mathrm{Ola} \times \mathrm{C} 57 \mathrm{BL} / 6$ mixed background) were a generous gift from Edward M. Rubin (University of California at Berkeley, Berkeley, California, USA) (4). Mice lacking TP or IP individually were generated as described (19, 20). $A \mathrm{PoE}^{-/-}, \mathrm{TP}^{-/-}$, and $\mathrm{IP}^{-/-}$mice were backcrossed 5, 10, and 10 times, respectively, to $\mathrm{C} 57 \mathrm{BL} / 6 \mathrm{CrSlc}$ mice (Japan SLC). $\mathrm{TP}^{-/-}$and $\mathrm{IP}^{-/-}$mice were

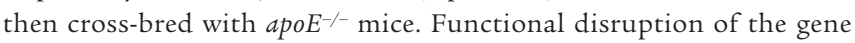
encoding apoE was confirmed by markedly elevated plasma cholesterol levels. Genotype analyses of apoE $E^{-/-}, \mathrm{TP}^{-/-}$, and $\mathrm{IP}^{-/-}$mice were performed by PCR using genomic DNA isolated from tail snip samples as a template. PCR analysis was performed for apoE alleles with the sense primers exon2 (5'-GTGCTGTTGGTCACATTGCTGACA-3') and Neo1 (5'-ATGGGATCGGCCATTGAACA-3') for WT and mutant alleles, respectively, and the antisense primer exon3 ( $5^{\prime}$-TCAGTTCTTGTGTGACTTGGGAGC-3'); for TP alleles with the sense primers ML139 (5'-ACTTTGTTGCAGACACCACCTGTC-3') and Neo2 (5'-TGATATTGCTGAAGAGCTTGGCGGCGA-3') for WT and mutant alleles, respectively, and the antisense primer ML136 (5'-AAGCTTGGGTTTCAGGGACCT-3'); and for IP alleles with the sense primer CY37 (5'-GTATCTTTCAGTACCTGAGGACTG-3') and 
the antisense primers CY41 (5'-GAGCAGAAAAATTCCCAGAGGCTT-3') and Neo17 (5'-TGACCGCTTCCTCGTGCTTTAC-3') for WT and mutant alleles, respectively (Figure 1A). Reaction mixtures contained $10 \mathrm{mM}$ Tris$\mathrm{HCl}, \mathrm{pH}$ 8.3, $50 \mathrm{mM} \mathrm{KCl}, 1.5 \mathrm{mM} \mathrm{MgCl} 2,0.1 \%$ Triton X-100, 10\% DMSO, $0.25 \mathrm{mM}$ dNTPs, 20 pmol of each primer, and $1 \mathrm{U}$ of Taq DNA polymerase (Toyobo) in a total volume of $20 \mu \mathrm{l}$. After a denaturation step at $94^{\circ} \mathrm{C}$ for 3 minutes, 35 cycles of the amplification step $\left(94^{\circ} \mathrm{C}\right.$ for 60 seconds, $58^{\circ} \mathrm{C}$ for 60 seconds, and $72^{\circ} \mathrm{C}$ for 80 seconds) were carried out, followed by a final elongation step of 3 minutes at $72^{\circ} \mathrm{C}$. For apoE alleles, primers exon2 and exon3 amplify a $0.7-\mathrm{kb}$ WT allele fragment, and primers Neo1 and exon3 amplify a 0.4-kb mutant allele fragment. For TP alleles, primers ML139 and ML136 amplify a 0.9-kb WT allele fragment, and primers Neo2 and ML136 amplify a 1.1-kb mutant allele fragment (Figure 1A). For IP alleles, primers CY37 and CY41 amplify a 1.3-kb WT allele fragment, and primers CY37 and Neo17 amplify a 0.9-kb mutant allele fragment (Figure 1A). Mice were kept on a 12-hour light/dark cycle and were fed a normal chow diet (F2; Funabashi Farm). Food and water were available ad libitum. All experiments were performed in male mice. All experimental procedures were approved by the Committee on Animal Research of Kyoto University Faculty of Medicine.

Preparation of mouse platelets and platelet aggregation assay. Platelet aggregation was examined as described previously (61). Blood $(1.0 \mathrm{ml})$ was drawn by cardiac puncture of ether-anesthetized mice with a syringe containing $50 \mu \mathrm{l}$ of $3.8 \%$ trisodium citrate. Blood pooled from 3-4 animals was diluted with an equal volume of modified Tyrode-HEPES buffer, pH 7.4 (20 mM HEPES, $140 \mathrm{mM} \mathrm{NaCl}, 5 \mathrm{mM} \mathrm{MgCl}_{2}$, and $5 \mathrm{mM} \mathrm{KCl}$ ). Platelet-rich plasma (PRP) was prepared by centrifugation at $160 \mathrm{~g}$ for 5 minutes at room temperature. Platelet-poor plasma was obtained by further centrifugation of the blood after PRP was removed at $1,500 \mathrm{~g}$ for 10 minutes at room temperature. The number of platelets in the PRP was adjusted to $3 \times 10^{5}$ platelets/ $\mu$ l. Platelet aggregation was measured with an aggregometer (NBS Hema Tracer 601; Tokyo Koden). I-BOP, a TP agonist, was used to activate platelets, and cicaprost, an IP agonist, was used to inhibit platelet aggregation.

Lipid and lipoprotein analyses. Blood $(1.0 \mathrm{ml})$ was drawn by cardiac puncture of ether-anesthetized mice into a tube containing EDTA (final concentration, $5 \mathrm{mM}$ ). Plasma was isolated by centrifugation at $1,500 \mathrm{~g}$ for 10 minutes and was maintained at $4{ }^{\circ} \mathrm{C}$. Plasma cholesterol and triglyceride were measured using Toyobo enzymatic assay kits (Toyobo). For quantification of the cholesterol content of each lipoprotein, lipoproteins were separated at buoyant densities of $1.019 \mathrm{~g} / \mathrm{ml}$ and $1.063 \mathrm{~g} / \mathrm{ml}$ by ultracentrifugation. VLDLC is the difference between TC and cholesterol with a density greater than $1.019 \mathrm{~g} / \mathrm{ml}$; HDLC is cholesterol with a density of more than $1.063 \mathrm{~g} / \mathrm{ml}$ cholesterol; LDLC is the difference between TC and the sum of VLDLC and HDLC.

Quantification of atherosclerosis. Atherosclerotic lesions were quantified by en face analysis of the whole aorta and by cross-sectional analysis of the proximal aorta and the innominate artery. For en face preparations of the aorta, a cannula was inserted into the left ventricle and the aortic tree was fixed by perfusion for $10 \mathrm{~min}$ with ice-cold PBS containing $4 \%$ paraformaldehyde (PFA), 5\% sucrose, $20 \mu \mathrm{M}$ butylated hydroxytoluene, and $2 \mu \mathrm{M}$ EDTA, as described previously $(62,63)$. The aorta was opened longitudinally, from the heart to the iliac arteries, while still attached to the heart and major branching arteries in the body. The primary incision followed the ventral side of the aorta and the inner curvature of the arch. To obtain a flat preparation for imaging, a second incision was made along the outer curvature of the arch. The aorta (from the heart to the iliac bifurcation) was then removed and was "pinned out" on a black wax surface in a dissecting pan using stainless steel pins $0.2 \mathrm{~mm}$ in diameter. After overnight fixation with the PFA solution described above and a 12- hour rinse in PBS, the aortas were briefly rinsed in $70 \%$ ethanol; immersed for 6 minutes in a filtered solution containing $0.5 \%$ Sudan IV, 35\% ethanol, and $50 \%$ acetone; and destained for 5 minutes in $80 \%$ ethanol. The Sudan IV-stained aortas were photographed and were used for quantification of atherosclerotic lesions.

For cross-sectional analysis of the aorta, hearts were isolated from mice sacrificed by cervical dislocation, were washed in PBS, and were embedded in OCT compound. The OCT-embedded hearts were sectioned with a cryostat, and $6-\mu \mathrm{m}$ sections in the proximal aorta were obtained sequentially beginning at the aortic valve. Sections were transferred onto a Superfrost slide (Matsunami) and were stained with oil red $\mathrm{O}$ followed by counterstaining with hematoxylin (4). Ten sections obtained every $36 \mu \mathrm{m}$ from the aortic sinus were used for quantification of lesion areas with Image Pro Plus software (Media Cybernetics). The average lesion area of the ten sections from each heart was taken as a value to represent that animal, and the means of the average lesion areas from each group were compared as described previously $(64,65)$.

Atherosclerotic lesions in the innominate artery were quantified by cross-sectional analysis. Innominate arteries were isolated from 45 -weekold male mice sacrificed by cervical dislocation, were washed in PBS, and were embedded in OCT compound. OCT-embedded innominate arteries were sectioned with a cryostat and 8 - $\mu \mathrm{m}$ sections were obtained sequentially. Sections were transferred onto a Superfrost slide and were stained with hematoxylin and eosin. Ten sections obtained every $80 \mu \mathrm{m}$ were used for quantification of lesion areas with Image Pro Plus software. The average lesion area of the 10 sections from each innominate artery was taken as a value to represent that animal and the means of the average lesion areas from 10 mice were compared.

Immunohistochemistry. For cross-sectional analyses, the aortic tree was perfused with ice-cold PBS containing $5 \mathrm{mM}$ EDTA via a cannula inserted into the left ventricle for 10 minutes. The aortic arch was isolated, embedded in OCT compound, and sectioned at a thickness of $6 \mu \mathrm{m}$ with a cryostat. Sections containing atherosclerotic plaques were identified by microscopy. These sections were then fixed in $4 \%$ PFA at $4^{\circ} \mathrm{C}$ for $10 \mathrm{~min}-$ utes, were immersed in PBS for 5 minutes for rehydration of the tissues, and were blocked overnight at $4{ }^{\circ} \mathrm{C}$ with $2 \%$ skim milk (BD) in PBS. For evaluation of the abundance of macrophages and SMCs and the expression of ICAM-1 (CD54) and PECAM-1 (CD31) in the lesions, sections were incubated overnight at $4{ }^{\circ} \mathrm{C}$ with a 1:200 dilution of rat MOMA- $2 \mathrm{mAb}$ against mouse macrophages (Accurate Chemical and Scientific Co.); a 1:200 dilution of mouse $1 \mathrm{~A} 4 \mathrm{mAb}$ against human $\alpha$-smooth muscle actin, labeled with FITC (Dako); a 1:200 dilution of armenian hamster mAb against mouse ICAM-1, labeled with Texas Red (BD); and a 1:200 dilution of rat mAb against mouse PECAM-1, labeled with FITC or Texas Red (BD). Sections incubated with MOMA-2 antibody were then washed and incubated with a 1:400 dilution of goat anti-rat IgG, labeled with Texas Red (BD). For vWF staining, endogenous peroxidase activity was blocked by incubation of sections at $4^{\circ} \mathrm{C}$ for 30 minutes with $0.3 \%$ (volume/volume) $\mathrm{H}_{2} \mathrm{O}_{2}$ in PBS. The sections were then incubated overnight at $4{ }^{\circ} \mathrm{C}$ with a 1:200 dilution of mouse mAb against human vWF, labeled with HRP (Sigma-Aldrich). After a thorough washing, staining was developed with diaminobenzidine followed by counterstaining with hematoxylin. Ten sections obtained every $18 \mu \mathrm{m}$ from aortic arch were used for quantification of the macrophages and SMCs and EC density of the lesions with Image-Pro Plus software. The macrophages and SMCs were quantified by measurement of the area that stained positive for the respective markers, as described previously (7). EC density was determined by the ratio of the vWF-positive luminal surface length to the total luminal surface length of each cross-sectional plaque. The average of the 10 sections was taken to represent 1 animal, and the means of the averages from each group were compared. 
For the en face analysis, the aortic tree was first washed by perfusion with ice-cold PBS containing $5 \mathrm{mM}$ EDTA and then was fixed by perfusion with ice-cold PBS containing 4\% PFA via a cannula inserted into the left ventricle, each perfusion for 10 minutes. The aortic arch was isolated and opened longitudinally. En face preparations were blocked overnight at $4^{\circ} \mathrm{C}$ with $2 \%$ skim milk in PBS and were incubated overnight at $4^{\circ} \mathrm{C}$ with a 1:500 dilution of rat $\mathrm{mAb}$ against mouse PECAM-1, labeled with FITC, and armenian hamster mAb against mouse ICAM-1, labeled with Texas Red. Because activation of ECs occurs on the "shoulder" of plaques (66), five images $(1,024 \times 1,024$ pixels/image) were obtained randomly from the EC monolayer on the "shoulder" of plaques with a Bio-Rad MRC-1024 confo$\mathrm{cal}$ microscope. The average pixel intensity of the five images was taken as a value to represent that animal, and the means of the average pixel intensity from each group were compared as described previously (60).

Silver nitrate staining of en face endothelial cells. The aortic tree was washed, stained, and fixed as described previously $(67,68)$ by successive perfusion in the following solutions: $10 \mathrm{ml}$ of $5 \%$ glucose; $4 \mathrm{ml}$ of $0.25 \%$ silver nitrate; $2 \mathrm{ml}$ of $5 \%$ glucose; $8 \mathrm{ml}$ of $3 \%$ cobalt bromide and $1 \%$ ammonium bromide; $2 \mathrm{ml}$ of $5 \%$ glucose; $4 \mathrm{ml}$ of $4 \%$ PFA; $10 \mathrm{ml}$ of distilled water; $2 \mathrm{ml}$ of hematoxylin; and $10 \mathrm{ml}$ of distilled water. The aortic arch was isolated, opened longitudinally, and mounted with the endothelium upward on a Superfrost slide.

Scanning electron microscopy. The aortic trees of 20-week-old male mice were washed at $37^{\circ} \mathrm{C}$ for 10 minutes with PBS and were fixed at room temperature for 10 minutes with PBS containing $1 \%$ glutaraldehyde by perfusion, as described previously (69). The aortic tree was then excised, opened longitudinally, additionally fixed by immersion in PBS containing $1 \%$ glutaraldehyde at room temperature for 24 hours, dehydrated in ethanol, and processed by critical point drying with $\mathrm{CO}_{2}$. The aortic tree specimens were then oriented with the lumens exposed, mounted with carbon paint, and coated with gold for scanning electron microscopy (T-330; Nippon Denshi).

Flow cytometry for platelet reactivity. Platelet reactivity was examined by whole-blood flow cytometry $(32,33)$. Blood $(1.0 \mathrm{ml})$ was drawn by cardiac puncture of ether-anesthetized mice with a syringe containing $50 \mu \mathrm{l}$ of $3.8 \%$ trisodium citrate. Within 10 minutes of being drawn, the blood was diluted 1:4 in modified Tyrode-HEPES buffer, $\mathrm{pH} 7.4$, and the diluted blood was activated at $37^{\circ} \mathrm{C}$ for 10 minutes with $0.1-0.5 \mathrm{U} / \mathrm{ml}$ thrombin, incubated at room temperature for 30 minutes with a 1:100 dilution of rat $\mathrm{mAb}$ against mouse P-selectin, labeled with FITC, and fixed at $4{ }^{\circ} \mathrm{C}$ for 2 hours with ice-cold PBS containing $1 \%$ PFA. Samples were then analyzed using a FACSVantage flow cytometer (BD).

Intravital microscopy. Leukocyte-EC interaction was examined by intravital microscopy using rhodamine $6 \mathrm{G}$ that stained in vivo leukocytes, as described previously $(29,60,69)$. Five male mice $25-30$ weeks of age were used for each strain. Rhodamine $6 \mathrm{G}$ was injected i.v., and the numbers of leukocytes rolling on and adhering to the wall of the common carotid artery were examined "off-line" during video playback analysis. A leukocyte was defined as rolling if it migrated along the vessel wall at a rate less than $200 \mu \mathrm{m} / \mathrm{s}$ and as adhering if it remained stationary for more than 20 seconds. We counted the number of leukocyte rolling and adhering in the artery per microscope field $(\times 100)$ and expressed the results as the number of leukocytes observed per $\mathrm{mm}^{2}$ area per minute.

Statistical analysis. Data are presented as means \pm SEM. Comparison of two groups was analyzed by Student's $t$ test. For comparison of more than two groups with comparable variances, one-way ANOVA was performed, followed by Tukey's $t$ test to evaluate pair-wise group differences. An associated probability ( $P$ value) of less than 0.05 was considered significant. Analyses were performed with the use of GraphPad Software Prism 3.0.

\section{Acknowledgments}

We are grateful to H. Wise for helpful discussions; K. Deguchi, T. Fujiwara, and N. Kitagawa for animal care and breeding; and T. Arai, H. Nose, and Y. Kitagawa for secretarial assistance. This work was supported in part by Grants-in-Aid for Scientific Research from the Ministry of Education, Science, Sports and Culture of Japan and by grants from the Organization for Pharmaceutical Safety and Research and the Kowa Life Science Foundation.

Received for publication March 1, 2004, and accepted in revised form July 27, 2004.

Address correspondence to: Shuh Narumiya, Department of Pharmacology, Kyoto University Faculty of Medicine, Yoshida, Sakyoku, Kyoto 606-8501, Japan. Phone: +81-75-753-4392; Fax: +81-75753-4693; E-mail: snaru@mfour.med.kyoto-u.ac.jp.
1. Ross, R. 1999. Atherosclerosis is an inflammatory disease. Am. Heart. J. 138:S419-S420.

2. FitzGerald, G.A., Smith, B., Pedersen, A.K., and Brash, A.R. 1984. Increased prostacyclin biosynthesis in patients with severe atherosclerosis and platelet activation. N. Engl. J. Med. 310:1065-1068.

3. Belton, O., Byrne, D., Kearney, D., Leahy, A., and Fitzgerald, D.J. 2000. Cyclooxygenase-1 and -2dependent prostacyclin formation in patients with atherosclerosis. Circulation. 102:840-845.

4. Plump, A.S., et al. 1992. Severe hypercholesterolemia and atherosclerosis in apolipoprotein E-deficient mice created by homologous recombination in ES cells. Cell. 71:343-353.

5. Zhang, S.H., Reddick, R.L., Piedrahita, J.A., and Maeda, N. 1992. Spontaneous hypercholesterolemia and arterial lesions in mice lacking apolipoprotein E. Science. 258:468-471.

6. Ishibashi, S., et al. 1993. Hypercholesterolemia in low density lipoprotein receptor knockout mice and its reversal by adenovirus-mediated gene delivery. J. Clin. Invest. 92:883-893.

7. Cyrus, T., et al. 2002. Effect of low-dose aspirin on vascular inflammation, plaque stability, and atherogenesis in low-density lipoprotein receptordeficient mice. Circulation. 106:1282-1287.

8. Cayatte, A.J., et al. 2000. The thromboxane recep- tor antagonist S18886 but not aspirin inhibits atherogenesis in apo E-deficient mice: evidence that eicosanoids other than thromboxane contribute to atherosclerosis. Arterioscler. Thromb. Vasc. Biol. 20:1724-1728.

9. Vane, J.R., Bakhle, Y.S., and Botting, R.M. 1998. Cyclooxygenases 1 and 2. Ann. Rev. Pharmacol. Toxicol. 38:97-120.

10. McAdam, B.F., et al. 1999. Systemic biosynthesis of prostacyclin by cyclooxygenase (COX)-2: the human pharmacology of a selective inhibitor of COX-2. Proc. Natl. Acad. Sci. U. S. A. 96:272-277.

11. Topper, J.N., Cai, J., Falb, D., and Gimbrone, M.A., Jr. 1996. Identification of vascular endothelial genes differentially responsive to fluid mechanical stimuli: cyclooxygenase- 2 , manganese superoxide dismutase, and endothelial cell nitric oxide synthase are selectively up-regulated by steady laminar shear stress. Proc. Natl. Acad. Sci. U. S. A. 93:10417-10422.

12. Foeldvari, I. 2002. A selective COX-2 inhibitor, meloxicam, as a treatment option in patients with juvenile idiopathic arthritis and gastrointestinal side effects from naproxen [letter]. Clin. Exp. Rheumatol. 20:874.

13. Mukherjee, D., Nissen, S.E., and Topol, E.J. 2001 Risk of cardiovascular events associated with selec- tive COX-2 inhibitors. JAMA. 286:954-959.

14. Rott, D., et al. 2003. Effects of MF-tricyclic, a selective cyclooxygenase- 2 inhibitor, on atherosclerosis progression and susceptibility to cytomegalovirus replication in apolipoprotein-E knockout mice. J. Am. Coll. Cardiol. 41:1812-1819.

15. Burleigh, M.E., et al. 2002. Cyclooxygenase- 2 promotes early atherosclerotic lesion formation in LDL receptor-deficient mice. Circulation. 105:1816-1823.

16. Pratico, D., Tillmann, C., Zhang, Z.B., Li, H., and FitzGerald, G.A. 2001. Acceleration of atherogenesis by COX-1-dependent prostanoid formation in low density lipoprotein receptor knockout mice. Proc. Natl. Acad. Sci. U. S. A. 98:3358-3363.

17. Belton, O.A., Duffy, A., Toomey, S., and Fitzgerald, D.J. 2003. Cyclooxygenase isoforms and platelet vessel wall interactions in the apolipoprotein E knockout mouse model of atherosclerosis. Circulation. 108:3017-3023.

18. Narumiya, S., Sugimoto, Y., and Ushikubi, F. 1999. Prostanoid receptors: structures, properties, and functions. Physiol. Rev. 79:1193-1226.

19. Kabashima, K., et al. 2003. Thromboxane $\mathrm{A}_{2}$ modulates interaction of dendritic cells and T cells and regulates acquired immunity. Nat. Immunol. 4:694-701.

20. Murata, T., et al. 1997. Altered pain perception and inflammatory response in mice lacking 
prostacyclin receptor. Nature. 388:678-682.

21. Shinomiya, S., et al. 2001. Regulation of TNF $\alpha$ and interleukin- 10 production by prostaglandins $\mathrm{I}_{2}$ and $\mathrm{E}_{2}$ : studies with prostaglandin receptor-deficient mice and prostaglandin E-receptor subtypeselective synthetic agonists. Biochem. Pharmacol. 61:1153-1160.

22. Fujino, T., et al. 2002. Effects of the prostanoids on the proliferation or hypertrophy of cultured murine aortic smooth muscle cells. Br. J. Pharmacol. 136:530-539.

23. Hoshikwa, Y., et al. 2001. Prostacyclin receptor-dependent modulation of pulmonary vascular remodeling. Am. J. Respir. Crit. Care. Med. 164:314-318.

24. Xiao, C.Y., et al. 2001. Roles of prostaglandin $\mathrm{I}_{2}$ and thromboxane $\mathrm{A}_{2}$ in cardiac ischemia-reperfusion injury: a study using mice lacking their respective receptors. Circulation. 104:2210-2215.

25. Takahashi, Y., et al. 2002. Augmentation of allergic inflammation in prostanoid IP receptor deficient mice. Br. J. Pharmacol. 137:315-322.

26. Nagao, K., et al. 2003. Role of prostaglandin $I_{2}$ in airway remodeling induced by repeated allergen challenge in mice. Am. J. Respir. Cell Mol. Biol. 29:314-320.

27. Arai, K., et al. 2003. Endogenous prostaglandin $I_{2}$ regulates the neural emergency system through release of calcitonin gene related peptide. Gut. 52:1242-1249.

28. Yamada, T., et al. 2003. Thromboxane $A_{2}$ regulates vascular tone via its inhibitory effect on the expression of inducible nitric oxide synthase. Circulation. 108:2381-2386.

29. Katagiri, H., et al. 2004. Role of thromboxane derived from COX-1 and - 2 in hepatic microcirculatory dysfunction during endotoxemia in mice. Hepatology. 39:139-150

30. Rosenfeld, M.E., et al. 2000. Advanced atherosclerotic lesions in the innominate artery of the apoE knockout mouse. Arterioscler. Thromb. Vasc. Biol. 20:2587-2592.

31. Cheng, Y., et al. 2002. Role of prostacyclin in the cardiovascular response to thromboxane $\mathrm{A}_{2}$. Science. 296:539-541.

32. Nakashima, Y., Plump, A.S., Raines, E.W., Breslow, J.L., and Ross, R. 1994. ApoE-deficient mice develop lesions of all phases of atherosclerosis throughout the arterial tree. Arterioscler. Thromb. 14:133-140.

33. Pratico, D., Cyrus, T., Li, H., and FitzGerald, G.A 2000. Endogenous biosynthesis of thromboxane and prostacyclin in 2 distinct murine models of atherosclerosis. Blood. 96:3823-3826.

34. Libby, P., Schoenbeck, U., Mach, F., Selwyn, A.P., and Ganz, P. 1998. Current concepts in cardiovascular pathology: the role of LDL cholesterol in plaque rupture and stabilization. Am. J. Med. 104:14S-18S

35. Hartung, H.P., Kladetzky, R.G., Melnik, B., and Hennerici, M. 1986. Stimulation of the scavenger receptor on monocytes-macrophages evokes release of arachidonic acid metabolites and reduced oxygen species. Lab. Invest. 55:209-216.

36. Fitzgerald, D.J., Roy, L., Catella, F., and FitzGerald, G.A. 1986. Platelet activation in unstable coronary disease. N. Engl. J. Med. 315:983-989.

37. Cipollone, F., et al. 2001. Overexpression of functionally coupled cyclooxygenase- 2 and prostaglandin E synthase in symptomatic atherosclerotic plaques as a basis of prostaglandin $\mathrm{E}_{2}$-dependent plaque instability. Circulation. 104:921-927.
38. Cipollone, F., et al. 2003. The receptor RAGE as a progression factor amplifying arachidonatedependent inflammatory and proteolytic response in human atherosclerotic plaques: role of glycemic control. Circulation. 108:1070-1077.

39. Kitahara, M., et al. 2001. Prostacyclin inhibits the production of MMP-9 induced by phorbol ester through protein kinase A activation, but does not affect the production of MMP-2 in human cultured mesangial cells. Kidney Blood Press. Res. 24:18-26.

40. Schermuly, R. T., et al. 2004. Antiremodeling effects of iloprost and the dual-selective phosphodiesterase $3 / 4$ inhibitor tolafentrine in chronic experimental pulmonary hypertension. Circ. Res. 94:1101-1108.

41. Trip, M.D., Cats, V.M., van Capelle, F.J., and Vreeken, J. 1990. Platelet hyperreactivity and prognosis in survivors of myocardial infarction. N. Engl. J. Med. 322:1549-1554.

42. van Zanten, G.H., et al. 1994. Increased platelet deposition on atherosclerotic coronary arteries. J. Clin. Invest. 93:615-632.

43. Broijersen, A., Hamsten, A., Eriksson, M., Angelin, B., and Hjemdahl, P. 1998. Platelet activity in vivo in hyperlipoproteinemia-importance of combined hyperlipidemia. Thromb. Haemost. 79:268-275.

44. Broijersen, A., Karpe, F., Hamsten, A., Goodall, A.H., and Hjemdahl, P. 1998. Alimentary lipemia enhances the membrane expression of platelet P-selectin without affecting other markers of platelet activation. Atherosclerosis. 137:107-113.

45. Poston, R.N., Haskard, D.O., Coucher, J.R., Gall, N.P., and Johnson-Tidey, R.R. 1992. Expression of intercellular adhesion molecule-1 in atherosclerotic plaques. Am. J. Pathol. 140:665-673.

46. Morisaki, N., et al. 1997. New indices of ischemic heart disease and aging: studies on the serum levels of soluble intercellular adhesion molecule-1 (ICAM-1) and soluble vascular cell adhesion molecule- 1 (VCAM-1) in patients with hypercholesterolemia and ischemic heart disease. Atherosclerosis. 131:43-48.

47. Collins, R.G., et al. 2000. P-Selectin or intercellular adhesion molecule (ICAM)-1 deficiency substantially protects against atherosclerosis in apolipoprotein E-deficient mice. J. Exp. Med. 191:189-194

48. Springer, T.A. 1990. Adhesion receptors of the immune system. Nature. 346:425-434.

49. Della Bella, S., et al. 2001. Novel mode of action of iloprost: in vitro down-regulation of endothelia cell adhesion molecules. Prostaglandins Other Lipid Mediat. 65:73-83.

50. Ishizuka, T., et al. 1998. Stimulation with thromboxane $\mathrm{A}_{2}\left(\mathrm{TXA}_{2}\right)$ receptor agonist enhances ICAM-1, VCAM-1 or ELAM-1 expression by human vascular endothelial cells. Clin. Exp. Immunol. 112:464-470

51. Mitsuhashi, M., et al. 2001. Necessity of thromboxane $\mathrm{A}_{2}$ for initiation of platelet-mediated contact sensitivity: dual activation of platelets and vascular endothelial cells. J. Immunol. 166:617-623.

52. Muller, W.A., Weigl, S.A., Deng, X., and Phillips, D.M. 1993. PECAM-1 is required for transendothelial migration of leukocytes. J. Exp. Med. 178:449-460.

53. Duncan, G.S., et al. 1999. Genetic evidence for functional redundancy of platelet/endothelial cell adhesion molecule-1 (PECAM-1): CD31-deficient mice reveal PECAM-1 dependent and PECAM-1-independent functions. J. Immunol. 162:3022-3030.

54. Graesser, D., et al. 2002. Altered vascular permeability and early onset of experimental autoim- mune encephalomyelitis in PECAM-1-deficient mice. J. Clin. Invest. 109:383-392. doi:10.1172/ JCI200213595

55. Ensminger, S.M., et al. 2002. Platelet-endothelial cell adhesion molecule-1 (CD31) expression on donor endothelial cells attenuates the development of transplant arteriosclerosis. Transplantation. 74:1267-1273.

56. Newman, P.J. 1999. Switched at birth: a new family for PECAM-1. J. Clin. Invest. 103:5-9.

57. Rival, Y., Del Maschio, A., Rabiet, M.J., Dejana, E., and Duperray, A. 1996. Inhibition of platelet endothelial cell adhesion molecule-1 synthesis and leukocyte transmigration in endothelial cells by the combined action of TNF- $\alpha$ and IFN- $\gamma$. J. Immunol. 157:1233-1241.

58. Ma, H., et al. 2001. Increased bleeding tendency and decreased susceptibility to thromboembolism in mice lacking the prostaglandin E receptor subtype EP3. Circulation. 104:1176-1180.

59. Palinski, W., et al. 1994. ApoE-deficient mice are a model of lipoprotein oxidation in atherogenesis. Demonstration of oxidation-specific epitopes in lesions and high titers of autoantibodies to malondialdehyde-lysine in serum. Arterioscler. Thromb. 14:605-616.

60. Tangirala, R.K., Rubin, E.M., and Palinski, W. 1995. Quantitation of atherosclerosis in murine models: correlation between lesions in the aortic origin and in the entire aorta, and differences in the extent of lesions between sexes in LDL receptor-deficient and apolipoprotein E-deficient mice. J. Lipid Res. 36:2320-2328.

61. Sano, H., et al. 2001. Functional blockade of platelet-derived growth factor receptor- $\beta$ but not of receptor- $\alpha$ prevents vascular smooth muscle cell accumulation in fibrous cap lesions in apolipoprotein E-deficient mice. Circulation. 103:2955-2960

62. Murayama, T., et al. 2000. Over expression of low density lipoprotein receptor eliminates apolipoprotein B100-containing lipoproteins from circulation and markedly prevents early atherogenesis in apolipoprotein E-deficient mice. Atherosclerosis. 153:295-302.

63. Nakashima, Y., Raines, E.W., Plump, A.S., Breslow, J.L., and Ross, R. 1998. Upregulation of VCAM-1 and ICAM-1 at atherosclerosis-prone sites on the endothelium in the ApoE-deficient mouse. Arterioscler. Thromb. Vasc. Biol. 18:842-851.

64. Huo, Y., et al. 2003. Circulating activated platelets exacerbate atherosclerosis in mice deficient in apolipoprotein E. Nat. Med. 9:61-67.

65. Furchgott, R.F., and Zawadzki, J.V. 1980. The obligatory role of endothelial cells in the relaxation of arterial smooth muscle by acetylcholine. Nature. 288:373-376.

66. Poole, J.C.F., Sanders, A.G., and Florey, H.W. 1958. The regeneration of aortic endothelium. J. Pathol. Bacteriol. 75:133-143.

67. Massberg, S., et al. 2003. A crucial role of glycoprotein VI for platelet recruitment to the injured arterial wall in vivo. J. Exp. Med. 197:41-49

68. Furman, M.I., et al. 1998. Increased platelet reactivity and circulating monocyte-platelet aggregates in patients with stable coronary artery disease. J. Am. Coll. Cardiol. 31:352-358.

69. Michelson, A.D., and Furman, M.I. 1999. Laboratory markers of platelet activation and their clinical significance. Curr. Opin. Hematol. 6:342-348. 